NBER WORKING PAPER SERIES

\title{
INTRA-DAY SEASONALITY IN ACTIVITIES OF THE FOREIGN EXCHANGE MARKETS: EVIDENCE FROM THE ELECTRONIC BROKING SYSTEM
}

\author{
Takatoshi Ito \\ Yuko Hashimoto \\ Working Paper 12413 \\ http://www.nber.org/papers/w12413 \\ NATIONAL BUREAU OF ECONOMIC RESEARCH \\ 1050 Massachusetts Avenue \\ Cambridge, MA 02138 \\ July 2006
}

The authors are grateful to EBS for providing a proprietary data set for this academic purpose and to EBS analysts in New York for guidance on the nature of the data. The paper was presented at the NBER-TRIO conference in Tokyo December 9-10, 2005 and the Japanese Economic Association Spring Meeting, June 3-4, 2006. We are grateful to Robert Engle, Paolo Pesenti, Andy Rose, Richard Portes, and Tsutomu Watanabe for their comments and suggestions. Helpful comments from Professor Charles Goodhart and Bob Rankin (Reserve Bank of Australia) during the preparatory stage were appreciated. We are also grateful to Graham Elliott, Rich Lyons, Ryan Love and participants of seminars at the Bank of England and Osaka University for their comments and suggestions on an earlier version of the paper. Ito gratefully acknowledges financial support from the Japan Society for the Promotion of Science, Grants-in-aid, Basic Research (A-2-15203008). Hashimoto gratefully acknowledges financial supports from the Japan Society for the Promotion of Science, Grants-in-aid for Young Scientists (B17730211). The views expressed herein are those of the author(s) and do not necessarily reflect the views of the National Bureau of Economic Research.

(C2006 by Takatoshi Ito and Yuko Hashimoto. All rights reserved. Short sections of text, not to exceed two paragraphs, may be quoted without explicit permission provided that full credit, including $\odot$ notice, is given to the source. 
Intra-Day Seasonality in Activities of the Foreign Exchange Markets: Evidence From the Electronic Broking System

Takatoshi Ito and Yuko Hashimoto

NBER Working Paper No. 12413

July 2006

JEL No. F31, F33, G15

\begin{abstract}
$\underline{\text { ABSTRACT }}$
This paper examines intra-day patterns of the exchange rate behavior, using the "firm" bid-ask quotes and transactions of USD-JPY and Euro-USD recorded in the electronic broking system of the spot foreign exchange markets. The U-shape of intra-day activities (deals and price changes) and return volatility is confirmed for Tokyo and London participants, but not for New York participants. Activities and volatility do not increase toward the end of business hours in the New York market, even on Fridays (ahead of weekend hours of non-trading). It is found that there exists a high positive correlation between volatility and activities and a negative correlation between volatility and the bid-ask spread. A negative correlation is observed between the number of deals and the width of bid-ask spread during business hours.
\end{abstract}

Takatoshi Ito

Faculty of Economics

University of Tokyo

7-3-1 Hongo, Bunkyo-ku

Tokyo, 113-0033

JAPAN

and NBER

tito@e.u-tokyo.ac.jp

Yuko Hashimoto

Faculty of Economics

Toyo University

5-28-20 Hakusan, Bunkyo-ku

Tokyo, 112-8606

JAPAN

yhashi@toyonet.toyo.ac.jp 


\section{Introduction}

The foreign exchange market remains sleepless. Someone is trading somewhere all the time-24 hours a day, (almost) 7 days a week. Analyzing the behavior of the exchange rate has become a popular sport of international finance researchers, while global financial institutions are investing millions of dollars to build a real-time computer trading scheme. High-frequency, reliable data are the key in finding robust results for researchers or profitable schemes for businesses.

The objective of this paper is to analyze intra-day patterns, or seasonality, of market activities - frequency of quote revisions, transaction volumes, volatility, and bid-ask spread - of the dollar/yen and the euro/dollar spot exchange rates using a newly available data of the electronic broking system for the spot foreign exchanges. ${ }^{1}$ The intra-day seasonality is in itself interesting but it serves as a basis for further theoretical and empirical analysis. ${ }^{2}$ Some of our findings will be confirmation of what has been established in the literature with less reliable data, and some results, concerning behavior of the bid-ask spread, are new.

The overwhelming majority of the spot foreign exchanges are now transacted through the global electronic broking systems - the EBS and Reuters D3000. The data, provided by the EBS, consist of global electronic broking bid-ask quotes, lowest given and highest paid transaction prices, and transaction volumes for three years starting January 01, 1999 at the frequency of every one minute. ${ }^{3}$ The EBS data set has advantage over the frequently-used, indicative quotes of a foreign exchange market tick-by-tick data set, such as FXFX of Reuters, in at least two important aspects. First, the quotes in the EBS data set are "firm", in that banks that post quotes are committed to trade at those quoted prices, when they are "hit". ${ }^{4}$ In contrast, the indicative quotes of FXFX screen are those input by dealers for information only, without any commitment for trade. Indicative quotes are much less reliable than firm quotes in capturing the whole picture of market reality. Second, transactions data available in the EBS data set is simply not

\footnotetext{
${ }^{1}$ The EBS notations define the base currency as the first currency in the name of the currency pair. Note that trading in EBS is done in millions of the base currency.

${ }^{2}$ In an earlier paper of ours, Ito and Hashimoto (2004), we have analyzed intraday patterns without data set of trade volume shares, which will be described later. This paper is a much expanded version of our earlier paper with an additional data set. Although most of the contents are absorbed in this paper, this is practically new paper. The earlier paper will remain unpublished.

${ }^{3}$ The data set was provided for fee by the EBS Co., for the use at the University of Tokyo, Graduate School of Economics. The authors are grateful to EBS for such an arrangement.

${ }^{4}$ See Goodhart and O’Hara (1997: p.78) for general discussions on the difference between the indicative and firm quotes.
} 
available in the FXFX screen. Although exact trading volumes are not disclosed, transactions counts (counts of seconds that had at least one transaction) and trade volume shares (a daily percentage share of trading volumes in one minute) are available in the EBS data set.

The contribution of this paper to the literature is three-fold. First, the paper presents a careful description of intra-day seasonality (quote revisions, trading volumes, volatility, and bid-ask spread), taking into account time zone and daylight saving time of major markets, and national holidays. Over different GMT hours, quote revision frequency, trading volume, and return volatility are found to move together whereas the spread moves the opposite way, most of the time. Second, the U-shape pattern of quote revision frequency and trading volume shares is found for both Tokyo and London participants, but no daily U-shape patterns for New York participants. Effects of overlapping hours on price changes and transaction volumes seem to be large. Third, with regard to the intraday patterns of the bid-ask spread, the following tendencies were established for most hours during the day, except possibly the opening hour of the Tokyo market: a negative correlation between the number of deals and the width of bid-ask spread; the negative correlation between the bid-ask spread and price volatility. The discovery of the last correlation is interesting because it contrasts to an observed intra-day pattern in the equity market.

In FOREX market, activity (quote revision and trading) and volatility are highest in ordinary opening hours of all three markets, but there is no increase at the end of the day. This contrasts to the equity markets where activity is U-shaped with a rise at the end of the day as well as at the beginning. Another big difference between FOREX and equity markets is the correlation coefficient of the spread and activities (deals and price revisions). The paper finds that the spread is narrower during the hours of high activities in the FOREX market, and this is opposite of the conventional wisdom of the equity markets.

The rest of this paper is organized as follows: Section 2 describes the data. Section 3 establishes intra-day seasonality of activities. In section 4, various econometric tests are conducted to confirm statistically the patterns. Section 5 examines the London and New York opening effects, that is the extent of higher activity at the opening business hours. In section 6, we construct a theoretical model to explain how the overlapping business hours enhance the inter-regional trade. Section 7 concludes the paper. 


\section{The EBS data}

\subsection{EBS electronic broking system}

By early 2000s, almost all major currency spot trading have become matched by one of the two electronic broking systems, EBS and Reuters D-3000. ${ }^{5}$ The share of electronic trading is dramatically increasing and it should make researchers to reconsider how the theory should be formulated. ${ }^{6}$ The EBS is a provider of trading technology, and the quotes and transactions are shown continuously, 24 hours a day. The EBS trader's screen shows the "best bid" and the "best offer" of the market, that is, the bid and offer that are committed to trade by some dealer, and the "best bid for the dealer" and "best ask for the dealer”, that is, the bid and offer that are committed to trade if someone on the other side has credit line with you. ${ }^{7}$

The EBS has a very strong market share (in absolute terms and in comparison to Reuters D-3000) in the dollar/yen rate and the euro/dollar rate. ${ }^{8}$ Therefore, it is safe to

\footnotetext{
5 The various aspects of market transactions are surveyed for the month of April every three years by the Bank of International Settlements (BIS) with cooperation with national central banks. The surveys by the Bank of Japan on the Tokyo market shows that the yen total transaction volume in Tokyo in April 2001 was 146.8 billion, of which 122.7 billion yen was in the interbank market, and 24.1 billion yen was in the customer market. In the interbank market, 27.8 billion yen was spot trading, 10.7 billion yen was forward trading and 84.2 billion was swap trading. Of the spot interbank transactions, about half (13.4 billion yen) was done via electronic broker, another half (13.0 billion yen) was through direct dealing. The human broker diminished to be a minor segment (1.4 billion yen) of the market. The ratio of electronic broking transactions to total interbank spot trading has increased from $12.0 \%$ (1995) to $36.7 \%$ (1998), to $48.3 \%$ (2001). The ratio of electronic broking transactions to total broking transactions increased from 32.1\% (1995) to $79.3 \%$ (1998) to 91.0\% (2001). The Bank of Japan stopped the survey of the electronic trading in 2004. The Bank of England in the April 2004 survey estimates 66 percent of the interdealer spot business in the UK is conducted through electronic broking, while it was 34 percent in New York. (Bank of England, 2004, p.473).

${ }^{6}$ The BIS (2002) also mentions the impact of the widespread use of the electronic broker for the decline of the trading volumes from 1999 to 2001: "[decline in the transaction volume] can in part be explained by the growing role of electronic brokers in the spot interbank market. The use of electronic brokers implies that foreign exchange dealers generally need to trade less actively among themselves.” (BIS (2002: p.7). “Trading among themselves" was described as "hot potatoes" (Lyons (1997)), which had become less important due to the electronic trading. Our interviews (in November 2003) with banks with substantial foreign exchange trading in London reveals that they have reduced in the last few years the degree of discretion of dealers and shifted proprietary trading to the specialized section. Computer models have replaced dealers' instincts.

7 For the general reference on the microstructure of the foreign exchange market, see Goodhart and O'Hara (1997), Lyons (1995) and Lyons (2001). For earlier work that used the electronic broking system, see Goodhart, Ito and Payne (1996) and Goodhart and Payne (1996) have used the data obtained from Reuter D2000-2 that is predecessor of D3000.

${ }^{8}$ Reuters have significant market shares in exchanged related to sterling, Canadian dollar, and Australian dollars.
} 
assume that almost all electronically brokered spot deals of these two currencies are represented in the data set.

The EBS system facilitates, as part of the dealing rules, each institution to control its credit lines: trading in EBS can be done only between counterparties with bilateral credit but an institution can control only its own credit lines. Namely, each EBS-linked institution sets credit lines (including zero) against all other potential counter-parties. ${ }^{9}$ Therefore, an institution faces a restriction of bid, offer, or deal from other institutions. When market-best bid and offer rates are posted, they are not necessarily available to a particular participant of the EBS system. For example, a smaller or regional bank may have fewer trading relationships, thus not as many credit relationships. The EBS-registered dealer's screen shows the best bid and best offer for that particular institution, as well as those of the market. The bid and ask for that institution may be different from the market-best bid and best ask of the market. Our data set contain the market-best bids and offers. In normal times, the market-best bid of the market is lower than the best offer of the market. However, it is possible, and it does happen, that market-best bid price and ask price is reversed. ${ }^{10}$ The reversal does not necessarily mean the existence of risk-free profit opportunities. They may reflect that credit lines prevent the obvious arbitrage. We have eliminated such reversals from the sample.

\subsection{The EBS Data Set ${ }^{11}$}

The EBS has made available to us two sets of data, the price data set and the trade volume share data set. Both data sets include information on the dollar/yen and the euro/dollar currency pairs from January 1, 1999 to December 31, 2001. The price data set is the first to become available to several researchers on the firm quotes in high frequency. $^{12}$ It contains information of, among others, best bid, best ask, deal prices

\footnotetext{
${ }^{9}$ Also, as part of facilitating an orderly market, EBS requires any newly linked institution to secure a sufficient number of other banks that are willing to open credit lines with the new comer.

10 This reversal may be caused by aggressive pricing (higher bids or lower asks) by smaller, local banks because they will have relatively fewer credit relationships, implying that they will see fewer dealable prices generally.

${ }^{11}$ The data set is a proprietary information of EBS. The usage is restricted to those who are affiliated at the University of Tokyo.

${ }^{12}$ Data are of the 1-second time slice. The system records, at every second, bid, offer, deals that are posted and carried out in the world-wide EBS system. The quote data (Bid and offer) are the best prices from the electronic order book recorded at the end of time slice. Fluctuations of the bid and offer rates within the second (in the time slice) are not recorded and cannot be inferred. It is theoretically possible that bid and offer rates move up and down within the second, but not shown in the data set. Deal rates are recorded on the basis of Highest Paid and Lowest Given in the 1-second time slice.
} 
done on the bid side (lowest given) and deal prices done on the ask side (highest paid). ${ }^{13}$ Moreover, the EBS price history shows whether the deal is done on the bid side (the bid was taken) or the ask side. The price data set does not contain information on the volume of transactions associated with bid, offer, or deal.

The basic characteristics of the data used in this study are shown in Table 1. "The number of price changes" means the number of quote changes on either side of the bid-ask quotes or both at the same time. ${ }^{14}$

\section{Table 1}

The trade volume data set is also the first to become available on the trading volumes in high-frequency. It includes relative trade volume shares that are the share of trade volumes (one-minute slice) relative to the total trading volumes in that day. ${ }^{15}$

The EBS global system consists of three regional computer sites, based in Tokyo, London, and New York, and it matches orders either within the site or across different sites. Each region covers Europe, North America, and Asia, respectively. The three regions are often abbreviated as LN, NY, and TY regions in this paper. The intra-regional deal of LN, for example, consists of deals whose maker and taker are both from London region. And inter-regional deal of LN\&NY consists of deals whose maker and taker are from two different regions of London and New York.

A relative share of trades between dealers in region $\mathrm{X}$ and $\mathrm{Y}$, where $\mathrm{X}$ and $\mathrm{Y}$ are one of the three regions, in minutes $\mathrm{s}$ is defined as those trading volumes (between $\mathrm{X}$ and $\mathrm{Y}$ in minutes $s$ ) divided by total trading volumes of that day. Therefore for each minutes, there are six intra- or inter-regional trading shares are available.

\footnotetext{
${ }^{13}$ The deal (on either side) recorded at $\mathrm{xx}$ second includes those that took place between $\mathrm{xx}-1$ second to $\mathrm{xx}$ second. When there are multiple trades within one second, "lowest given price" and "highest paid price" will be shown. A highest paid deal means the highest price hit (done) on the ask side within one second and the lowest given deal means the lowest price hit (done) on the bid side within one second.

${ }^{14}$ Price changes could be generated by new entries of quotes, withdrawal of former quotes or disappearance of the quote due to "hits". The difference between "the number of price changes" and the sum of "the number of price changes on the bid side" and "that on the ask side" is the number of quote changes on both sides simultaneously.

15 Since actual volumes in a second or a minute were not available, we use this relative measure. Admittedly, it is less informative. However, a picture of intra-day trading patterns using actual volumes may be only slightly different from ours.
} 
Table 2 shows the three-year average of relative daily volume percentages of the yen-dollar and the euro-dollar deals. Deal traffic patterns are described in terms of intra-regional deals as well as inter-regional deals. The relative deal volume of six pairs of three markets is shown as percentage of the total daily volume by region. Originally the percentage is shown in the one-minute timeslice basis. Then, in the analysis, it is hourly aggregated.

The first three rows show percentages of intra-regional deals of London, New York, and Tokyo. The next three rows show the three inter-regional pairs of three regions. The Relative Trade Share by region is the postulated share based on our calculation, in order to see the shares of deals that can be attributable to a particular region. It is calculated by adding the intra-regional deal share and the sum of halves of inter-regional deals. For example, the yen trade share in Tokyo market is the sum of the Tokyo intra-regional share, half of the Tokyo-NY, and the half of the Tokyo-London deal shares. In other words, one LN-TY transaction is divided into 0.5 Tokyo region deal and 0.5 London region deal.

\section{Table 2}

There are two salient features that emerge from this table. First, there is a home-market advantage, namely the yen is traded more by Tokyo financial institutions (Tokyo-Tokyo deals, Tokyo-London deals, in particular) and the euro is traded more by London financial institutions (London-London deals, London-New York deals, in particular). In total, $42 \%$ of yen trades are attributable to the Tokyo financial institutions (30\% for London), and 54\% of euro trades are attributable to the London financial institutions (14\% for Tokyo). The New York institutions participate in the deals less than the Tokyo institutions for the yen and less than London institutions for the euro transactions. Second, the overlapping business hours encourage inter-regional transactions. For both the yen and the euro, the London-New York deal share is the highest, and the Tokyo-New York deal share is the lowest. This reflects that business hours in London and New York overlap more than three active business hours, while Tokyo and New York does not share any business hour. 


\section{The Intra-day Patterns}

\subsection{The Literature}

The intraday patterns of volume, volatility, spread have been examined with data in the foreign exchange and stock markets theoretically and empirically by many papers. ${ }^{16} \mathrm{~A}$ seminal work by Admati and Pfeiderer (1988) provided a theory to explain why the concentration of trading and high volatility could happen in particular hours in a day using the model where there are three types of traders, discretionary liquidity traders, non-discretionary liquidity traders, and informed traders. Among other findings, they related their theoretical results to the U-shape pattern of volume and variance observed in New York Stock Exchange. We will argue later in this section of the paper that the high volume and variance at the end of the day is not observed, so that the U-shape is violated, in the foreign exchange market, unlike the stock market. Admati and Pfeiderer (1988) also predicted that the spreads should be lowest at the beginning of the day. Brock and Kleidon (1992) provides evidence that the bid-ask spread also shows the U-shape as volume, contradicting theoretical prediction of Admati and Pfeiderer. Hsieh and Kleidon (1996) presented the intra-day U-shape pattern of the bid-ask spread as well as the volatility of returns (mid point of the bid and ask quotes) of the Deutsche Mark/Dollar, namely they are positively correlated. They used the identity of institutions that provide quotes to show the U-shape of standard deviation of returns (Fig. 2.3) and spreads (Fig. 2.5) for market participants of particular region. Easley and O’Hara (1992) built a theoretical model where a lack of trade would induce a market maker to narrow the spread in the next period. This implies a positive correlation between the trading volume and the spread.

In this section, we will present several pieces of evidence. Some of them confirm what were found in the literature, while some contradict the above-mentioned results or theoretical predictions. First, we will show that during the first hour of the Tokyo market (or practically first hour of active trading of the day), bid-ask spreads are wider, considering the high trading volume and return volatility. This is consistent with an adverse selection model of Foster and Viswanathan (1990) and the stock market evidence of Foster and Viswanathan (1993), but inconsistent with the Admati and Pfeiderer prediction. We will show that the spreads of market best quotes show a negative correlation with volatility and trading volume in general within the day,

\footnotetext{
${ }^{16}$ Many papers are contained in a conference volume on the High Frequency Data in Finance, edited by Baillie and Dacorogna (1997). Hsieh and Kleidon (1996) provide a concise survey on the literature with regard to the existence and explanation of the U-shape pattern in addition to their empirical findings. We summarize their survey of the literature up to the point of their publication.
} 
contradicting the stock market evidence, except the opening hour of the Tokyo market where the spread is wider considering the very high volume and volatility.

When intra-daily data of indicative quotes became available, a large literature emerged examining the intraday patters of volatility and bid-ask spread. ${ }^{17}$ Among others, Andersen and Bollerslev (1997, 1998) and Baillie and Bollerslev (1990) show the patterns of intraday volatility, including calendar effects, Daylight Saving Time, Tokyo Opening effects and Tokyo Lunch time effects, and then proceeded to examine the dynamics of volatility clustering and other properties. These patterns will be reexamined in this paper with the data of better quality to be explained below.

All of the above-mentioned papers use the indicative quotes. This paper establishes the intraday patterns with "firm" (transactable) quotes and deals. Since they are direct observation of trading activities, results are much more reliable than those with indicative prices. There are only several papers that use the firm quotes, such as Goodhart, Ito, and Payne (1996) and Goodhart and Payne (1996). But their data consist of only one week of observations. Closest studies that used almost same data set are Berger, et al. (2005) and Chaboud, et al. (2004). Berger et al. (2005) showed the positive correlations between order flows and exchange rate movement. They examined whether the exchange rate appreciates if there are more buyer initiated trades (deals where the ask quotes were hit by buyers), and found that an excess of buyer-initiated trades is associated with a rising price.

It is known that macroeconomic statistical releases (announcements) sometimes move the exchange rate. Ito and Roley (1987) was the first to examine effects of surprise components in macroeconomic announcements both from the United States and Japan on the intra-day movement of the yen/dollar exchange rate. More recently, many papers have been written with improved data sets. Ansersen and Bollerslev (1998) and Andersen, Bollerslev, Diebold, and Vega (2003) examined the effect of macroeconomic announcement as well as intra-daily patterns of volatility, although both of them used the Reuters indicative quotes. Faust, et al. (2003), using high-frequency, but traditionally-available indicative quotes, studied the (joint) responses of the exchange rate, the interest rates and other asset prices at the time of macroeconomic announcements. They showed that a better than expected announcement in the US leads

\footnotetext{
17 Hsieh (1988) was one of the first papers that tried to characterize the exchange rate behavior. In the mid-1980s, the daily data of the exchange rates were considered to be high enough frequency.
} 
to the dollar appreciation, with lower relative risk premium for foreign currency or with expected future dollar depreciation. The finding was consistent with Dornbusch "overshooting." A similar study of effects of macroeconomic announcements was conducted with the EBS data set by Chaboud, et al. (2004). They associated the surge of trades and volatility to the macroeconomic announcements and other institutional features. Then, they established that the exchange rate responded to macroeconomic announcements very quickly, and the data releases tended to raise trading volumes, whether or not the content of the release was in line with expectation. They interpreted this as evidence of additional dimension of the data release beyond the surprise component that is associated with interpretation of the announcement, which takes time and actual trade. The exchange rate jumpd within a few minutes when the data announcement contained the surprise component. Again, the stronger than expected data was found to appreciate the currency, as was found in Andersen, et al. (2003) and Faust, et al. (2003). Andersen, et al. argued that the market reacts to news in an asymmetric way, namely "bad news has greater impact than good news.”

\subsection{Definition of Activity during the day}

In this section, the hourly changes in the market activities, the bid-ask spread and the volatility are examined. As for market activities, we will take the number of price changes (the number of seconds where price changes are recorded) and the number of deals (the sum of bid-side deals and ask-side deals) in each hour of the day, averaged over a particular period (mostly over a year) with a differentiation of the standard and daylight saving time. ${ }^{18}$ Similarly, the hourly bid-ask spread is averaged over the period (e.g., for one year). The volatility is defined as the average absolute 1-minute return for each one-hour interval. The 1-minute return is the change in the log of the mid-point of bid-ask quotes from minute $s-1$ to that of minute $s$, where minute $s$ is defined as the $s$ minute 00 second. These indicators of market activities are calculated for each GMT Hour (Hour 0 to 23), and then averaged over a certain period (mostly over a year). .

We also use the relative volume share of an hour, which is defined as hourly aggregated relative volumes in that day. The hourly trading volumes measured in the aggregate

\footnotetext{
${ }^{18}$ Note that the number of price changes and the number of deals in the data set may not exactly match the total number of price changes and deals in the EBS system, because the data set is in terms of the one-second slice. If there are more price changes and deals within one second, the recorded numbers are less than the true numbers. The original data set is by second. Therefore, the maximum number of deals or price changes in one hour is 3,600.
} 
deals in the numbers of contracts divided by the total trading volume (the number of contracts) of the day. ${ }^{19}$

The difference between the deal count and the trading volume share is two fold. The deal count is the number of seconds in which there is one deal or more. Therefore a second that experienced the deal may contain more than one deal and one deal may mean one million US dollars or several millions of US dollars. The trading volumes are the total amount of deals, but expressed in the share within the day.

A higher level of activities means frequent price changes, a larger number of deals, and a large number of trading volumes. The number of price changes by dealers tends to increase when more (heterogeneous) participants are in the market; when more news such as macroeconomic statistical announcements, become available; when the most competitive participant (who posts best bid and ask) is reacting to news and digest them; and when the bids and asks are hit more often (so that the best bids or asks are knocked out). The number of deals tends to increase when more participants with different expectations are present in the market (so that someone sells while someone buys at the same price); and when more news that can be interpreted differently become available to the market.

The bid-ask spread tends to become narrower when more participants are in the market (that is, market is deep) and when expectations for the changes in the following seconds are relatively homogeneous.

\subsection{Standard Time and Daylight Saving Time}

Since daylight saving time is adopted in London and in New York, the GMT hours corresponding to the local business hours of London and New York shift by one hour during their respective summer season. Table 3 summarizes the GMT hours and corresponding Local time of the three major markets.

\section{Table 3}

In the following, one year is divided into the two periods: ${ }^{20}$

19 On "contract" is one million of the base currency. For the case of the USD/JPY contract, the one million dollar contract is bought and sold.

${ }^{20}$ Daylight saving time in 1999 was from April 4 to October 31 in the United States; from March 28 
Daylight Saving (Summer) Time: First Sunday of April-last Sunday of October,

Standard (Winter) Time: January-last Sunday of March, the next working day of the last Sunday of October-December.

Note that we eliminate from the sample the one-week period in the spring when Europe is under the Summer Time but the US is not. Also excluded from the sample are Saturdays, Sundays, and days in which one of the three markets is closed for national holidays. $^{21}$

\subsection{Intraday Activity Patterns}

\section{Price changes and Deals}

Figures 1 and 2 show the intraday (Hour 0-23) pattern of the activities, the bid-ask spread and the volatility of the USD-JPY pair and Figures 3 and 4 show those of the Euro-USD pair. In the Figures, the return volatility is plotted by scaling 500 times the actual USD-JPY volatility and 400 times the actual Euro-USD volatility, in order to make them comparable in one Figure.

Figures 1 and 2 reveal several interesting features. First, a high correlation between the "number of price changes" and the "number of deals" is found in the yen-dollar foreign exchange market. Second, there are three peaks in the number of price changes and the number of deals in a day. In summer, peaks of the activity of USD-JPY pair are seen at Hour 0, Hours 6-7 and Hours 12-14; and in winter, Hour 0, Hour 8, and Hours 13-15. We also find three troughs in a day. In summer: Hour 3; Hours 10-11; and Hour 21: and in winter, Hour 3, Hour 11, and Hour 22. Third, there is a significant jump in activities at GMT Hour 0, or 9:00 a.m. Tokyo from Hour 23 of previous day, corresponding to the opening of the Tokyo foreign exchange market.

to October 31 in the United Kingdom; in 2000, from April 2 to October 29 in the United States, and from March 26 to October 29 in the United Kingdom; and in 2001, from April 1 to October 28 in the United States and from March 25 to October 28 in the United Kingdom.

${ }^{21}$ We drop the following holidays in addition to weekend days: for Christmas, December 30-January 2; plus the Japanese national holidays, i.e.,Coming-of-Age Day, National Foundation Day, Vernal Equinox Day, Greenery Day, Constitution Day, Children's Day, Marine Day, Respect-for-the Aged Day, Autumnal Equinox Day, Sports Day, Culture Day, Labor Thanksgiving Day, The Emperor's Birthday; for UK, St Patrick's Day, Good Friday, Easter, Easter Monday, Spring Bank Holiday, Summer Bank Holiday, Boxing Day (St Stephen's Day for Roman Catholics); and for US, Martin Luther King Day, President's Day, Memorial Day, Independence Day, Labor Day, Columbus Day, Veterans Day, Thanksgiving Day. 
Fourth, the bid-ask spread is narrower during the first half of the day, then it becomes wider after Hours 16-17 and peaks at Hours 21-22. Fifth, volatility moves very closely with market activities. Volatility also shows a jump at GMT Hour 0. It is smaller when market activities are less and higher when market is active.

In general, the bid-ask spread tends to be negatively correlated with the number of deals, the number of price changes and volatility: The three troughs of the number of deals (or price changes) mostly correspond to three peaks of the bid-ask spread. One slight exception is the Hour 0, when the bid-ask spread is higher than other business hours in Tokyo (except lunch hour at Hour 3) but the number of deals (or price changes) is at the one of the peaks; that is, unlike other times, a positive correlation. This will be examined in next section in details.

The literature, as surveyed in section 3.1., is divided in predicting lower or higher bid-ask spread in the first hour of trading, and the correlation of spread and volatility or volume. The picture clearly shows that the largest bid ask spread appears when the market activity is extremely low, namely, mid afternoon to evening of New York, GMT 18 to 22 hours. During more active hours, the bid-ask spread is higher in hours when the activities are low, namely the Tokyo lunch hour and London lunch hour. The bid-ask spread is narrowest when the market is busiest, the overlapping business hours of London and New York. Hsieh and Kleidon (1996) presented the intra-day U-shape pattern of the bid-ask spread of each regional dealers (London and New York). They associate the dealers' region as the identity of banks that put in the indicative quotes. However, they may represent not ready to transact quotes, basically the quotes that may be indicative of not active hours of that region. In the best transactable quotes like EBS bids and asks, the U-shape is not observable. The peak in the globally non-active hours, 18 to22 GMT hours, have the unambiguously high bid-ask spreads.

\section{Figures 1 and 2}

The decrease in activities during the Tokyo lunch hour is remarkable. There used to be regulations that prohibited the interbank foreign exchange trading during the lunch hour in Tokyo. Although the regulation was lifted in December 1994, the tradition seems to continue-history seems to matter. ${ }^{22}$

\footnotetext{
${ }^{22}$ Historically, the interbank foreign exchange transactions had a lunch break (regulatory shutdown) during the lunch hours. When the regulation was removed, the activities during the lunch hour
} 
Figures 3 and 4 show hourly-aggregated Euro-USD activities that correspond to the earlier figures for the USD-JPY pair. Similar observations emerge. First, a high correlation between the "number of price changes" and the "number of deals" is found. Second, as for the number of price changes and deals, three peaks on the hours similar to those of the USD-JPY pair, in a day are found, with one distinctive feature. The height of the first peak, Hour 0, is much lower for the Euro-USD pair than the USD-JPY. It is remarkable that during the peak hours in the London morning and the overlapping hours of London afternoon and New York morning, the number of deals (the sum of those on the bid and ask sides) exceeds that of price changes. This is evidence that the market is thick enough that many deals did not result in the price change. Third, we find three troughs in a day: at Tokyo lunch hour, London lunch hour, and at Hour 21-22. Fourth, the bid-ask spread is narrow during the London business hours. It becomes wider after Hours 16-17 and peaks at Hours 21-22.

\section{Figures 3 and 4}

In sum, comparing the USD-JPY and Euro-USD tradings, intraday activities of the two currency pairs show very similar patterns, with the following notable exceptions. First, there seems to be a "home-market advantage". That is, activities of the Tokyo market relative to the London market are higher for the USD-JPY and lower for the Euro-USD. In fact, the heights of the three peaks for the yen are roughly equal, but, for the euro, the height of the peak during the Tokyo opening hour is distinctively low. The Tokyo market (or to be precise, the Asian market in general) is not significant in the euro trading. Second, the Euro-USD market is particularly deep in London morning and even deeper in the London afternoon hours that overlap with the New York morning. This is shown in the number of deals exceeding the number of price change during London business hours. Such a characteristics is not generally observed in the USD-JPY trading (only once at Hour 8 in the 1999-2001 summer).

It is clearly seen from the Figures above, the correlation between bid-ask spreads and volatility is negative in the FOREX markets, which is completely opposite to the volatility pattern in equity markets. In equity markets, the correlation between spread

increased at the expense of those before and after; the net effect was higher. See Ito, Lyons, and Melvin (1998) and Covrig and Melvin (2005). Then, in the afternoon and market-ending hours of Tokyo market, activity again increases in terms of relative transaction volume: it peaks around Hours 5-6. 
and volatility is positive. When the market is volatile, the spreads tend to become wider. Dufour and Engle (2000), for example, find a positive correlation between volatility and spread for all 18 stocks used in the analysis. Engle and Patton (2004), using 100 NYSE stocks, also show that the active trades increase spreads. In equity markets, volume and volatility move together, and the activities show a $U$ shaped with rising at the end of the day as well as the beginning, and spreads are highest in the morning with a slight rise at the end of the day.

\section{Trade volume}

The above analysis is based on counts of deals and quote changes for the specific time interval. In the price data set, we cannot attribute the activities to specific locations (or, to be precise, market participants in the region). An example is whether a surge in activities in the Tokyo mid-afternoon hours and London morning hours can be attributable to activities of the Tokyo participants or the London participants. Fortunately, the data set of the trading volume shares has the label of participants (regional names) for the trading shares. ${ }^{23}$

The relative trading volume shares of deals that can be attributable to participants of a particular region for the USD-JPY pair are shown in Figures 5 and 6 . The volumes of yen trades done by Tokyo financial institutions and London financial institutions clearly show the U-shape patterns, respectively, whereas yen trade by New York financial institutions shows a single peak pattern. The peak of volume shares by the Tokyo participant (Hour 0) is higher than that by the London participants (Hours 7-8) or that by the New York participants (Hours 14-15). Tokyo participants remain in the market, although with low shares, during the London and New York business hours. The Tokyo participants start to trade the yen in the 7am Tokyo time (Hour 22), although a sudden surge at 9am is quite remarkable. The trading volume share by Tokyo financial institutions at 8am (Hour 23) is higher than that during the London business hours. The New York peak volume share is higher than that of the London volume share (Hour 12-13). The London and New York participants are quite dormant in the yen trading during the London business hours. ${ }^{24}$

\footnotetext{
${ }^{23}$ Jones, Kaul, and Lipson (1994) argue that it is the number of transactions, and not the size that cause the volatility using the stock market data. We have two measures, the counts of deals and the trading volume share. Both measures are highly correlated in our data set.

${ }^{24}$ The data set we used in our earlier study, Ito and Hashimoto (2004), did not distinguish the regional origins of the deals, and therefore the regional attribution remains only a conjecture.
} 


\section{Figures 5 and 6}

Figures 7 and 8 show the relative trading volume shares for the EURO-USD pair. It is immediately clear that the share of euro trades by the Tokyo participants is quite small. Although there is a U-shape pattern in the euro trading by the Tokyo participants, the shape and height of the U-shape is quite different from that for the yen-dollar trading. The Tokyo participants' share of Euro trading compared to that of the yen-dollar trading is low, and unlike the yen-dollar trading, the euro-dollar trading show that the trading share in the late afternoon hours (Hour 7 in the summer, Hour 6 in the winter) is higher than that of the beginning of the market (Hour 0). This shows that, for the euro trade, the Tokyo participants have to wait for London participants to find counterparties, whereas they can find among themselves the trading counterparties for the yen trade. In other words, for the yen-dollar trades, the Tokyo market has new information becoming available and heterogeneous reactions to the news generate trading, but for the euro trades, the Tokyo market relatively lacks news or has homogeneous participants.

\section{Figures 7 and 8}

The trading shares of the London participants are particularly high for the euro market during the two peaks (Hours 8 and 13-15 in winter; Hours 7 and 12-13 in summer). The trading shares of the New York participants show only a single peak (Hour 15 in winter and Hour 14 in summer). For the euro-dollar trading, the London participants' peak is higher than the New York participants' peak, while for the yen-dollar trading, the peak of the London participants' share is lower than the New York participants' share during the overlapping hours (Hours 13-15). Even for the euro trading, the London and New York participants are almost non-existent in the Tokyo business hours.

In sum, the trading volume share data show the following five salient features. First, a U-shape intra-day activity pattern is confirmed for the Tokyo and London market participants, but not for the New York market participants. ${ }^{25}$ The lack of a U-shape activity for New York market participants is a new finding in the microstructure literature. ${ }^{26}$ Second, there is a home-market bias in the foreign exchange market: the

\footnotetext{
25 The U-shape pattern was originally documented for the stock market. In the exchange market, see Hsieh and Kleidon (1996), and Ito, Lyons, and Melvin (1998).

26 For the empirical test and survey of the U-Shape pattern in financial markets, see Harris (1986), Foster and Viswanathan, (1993), Ito, Lyons and Melvin (1998), and Andersen and Bollerslev (1998).
} 
activity share for the yen trading is the highest by the Tokyo participants at the opening hours of the Tokyo market, while for the euro trading, the highest is by London participants during the overlapping hours of London afternoon and New York morning. Third, the relative trading share of the Tokyo market participants for the euro trading is significantly lower than the London or New York participants even in their peak hour. Fourth, the London and New York participants are quite dormant in their trading during the Tokyo market hours, while the Tokyo participants maintain some trading activities during the London business hours, both for the yen and euro trading. Fifth, comparing the number of seconds that include at least one deal (Figures 1 through 4) and the volume shares (aggregate of three regional participants, or a vertical sum of three points for each hour in Figures 5 to 8) quite similar patterns are found. Three peaks during the day for the yen-dollar trading, and two high peaks and one low peak for the euro-dollar trading.

\section{Tests of Intra-day Seasonality Patterns}

The number of market participants varies from one day to next, and from one hour to next within the day. There are conventional wisdoms regarding the depth of the market, market activities, and the bid-ask spread. When many market participants are participating in the market, the market is commonly called deep. When many participants with very different background and forecasts are present in the market, deals tend to occur. When there are many participants in the market, spreads tends to be narrower and trades do not change the best quotes. These common senses can be quantitatively tested and shown using our data. ${ }^{27}$

\subsection{Hypotheses}

Here, several hypotheses regarding intra-day patterns, such as the opening hour effects of the three markets, the Monday morning effect, and a (lack of) U-shape pattern are examined. The switch between the winter time and the daylight saving time will be exploited to identify opening hour effects of the London and NY markets apart from the GMT hour effects. (This cannot be done for the Tokyo opening effect, which is not distinguishable from the GMT Hour 0 dummy.) Also a hypothesis that the bid-ask

\footnotetext{
${ }^{27}$ Osler (2005) explained that when stop-loss orders are triggered the one-way movement of the exchange rate may result. This suggests that the relationship among volatility, volume and spread may change when the exchange rate changes per certain time period exceeds a threshold. However, we have not explored the possibility of nonlinear relationship.
} 
spread is narrower (wider) when the activity is higher (lower, respectively) is tested formally.

It is expected that the bid-ask spread is positively correlated with market activities. When many participants are present in the market, then the price changes will be frequent, and at the same time, spreads will become narrower. For the hours where the spreads are narrower, number of deals becomes high, because the difference in the opinion between the most bullish buyer and the most bearish seller is slim. When the bid-ask spread is small, a little perturbation in expectation or an arrival of small piece of information would trigger deals. Thus, the following relationships will be examined.

$$
\begin{aligned}
& \operatorname{Spread}_{(t)}=a_{0}+a_{1} * \text { Number of price changes }(t)+\varepsilon_{(t)}, \\
& \text { Number of deals }_{(t)}=b_{0}+b_{1} * \operatorname{Spread}_{(t)+} \varepsilon_{(t)} .
\end{aligned}
$$

We hasten to add that both the RHS and LHS variables have the same time segments, and endogeneity is not exactly dealt with properly.

However, there may be an exception to this relationship. When the Tokyo market opens after a long break, such as a weekend, the bid-ask spread may be wider because market participants are unsure about the market conditions and other participants' positions, while the numbers of deals and quote revisions may be higher, as some participants have to carry out some accumulated orders from customers.

\subsection{Are Tokyo Opening Hours Special?}

First of all, let us test whether the opening hour of the Tokyo market has special characteristics, because it follows a few hours of extremely low activity. The relationship between bid-ask spread and the number of price changes and the relationship between the number of deals and the bid-ask spread are assumed to have a stable relationship throughout the day, possibly except for the first business hour of the Tokyo market. Then the model for testing the Hour0 effect is specified as follows:

$$
\begin{gathered}
\text { Spread }_{(t)}=a_{0}+\left(a_{1}+a_{2} \text { HOdum }\right) * \text { Number of price changes }(t)+\varepsilon_{(t)}, \\
\text { Number of deals }_{(t)}=b_{0}+\left(b_{1}+b_{2} \text { HOdum }\right) * \operatorname{Spread}_{(t)+} \varepsilon_{(t)} .
\end{gathered}
$$


where HOdum is an hour 0 dummy, taking the value 1 when the quote is recorded in the period of Hour 0 (Tokyo 9am) and 0 otherwise. As explained above, it is supposed that the spread becomes narrower if a large number of dealers participate in the market, namely a large number of price changes, namely $a_{1}<0$, but this effect is weakened on the Hour 0 , namely $a_{2}<0$. Similarly, if the spread is narrower, then there is a greater chance for deals, $b_{1}<0$. If there is a pent-up orders to be executed in Tokyo at 9 am, after a hiatus of a few hours, then the H0 Dummy should have a positive impact on the trade, namely lessen the relationship between the spread and the deals. They are willing to trade even if the transactions costs, bid-ask spread, is high. This hypothesis is represented as $b_{2}>0$. During the opening hours of Tokyo (or Monday opening hours of Tokyo), the above relationship may be weakened and sign of dummy coefficients is expected to be positive. In the right hand side of the equations, a lagged dependent and independent variables are included Estimation results are shown in Table 4-1 (USD-JPY pair) and in Table 4-2 (EURO-USD pair). Panel A of tables shows the regression results of spread and price changes, and Panel $B$ shows the results of deals and spread. A separate regression is conducted for each of the three years.

\section{Table 4-1 Table 4-2}

As for the USD-JPY trade, shown in table 4-1, the statistically significant and negative coefficients of $a_{1}$ and $b_{1}$, as expected, are found. That is, when market is deep, that is, when the number of price changes is large, the bid-ask spread tends to be narrower, and when the spread is narrow, the number of deals is large. However, as shown in Panel A of Table 4-1, the Hodum is not estimated significantly positive. Instead, the results shows that the negative relationship between spread and the number of price changes is strengthened for USD-JPY during the Tokyo opening hours. In contrast, Panel B shows a positive and significant estimated H0 dummy. That is, even with a wider spread, market participants tend to deal during the Tokyo opening hours. This evidence is not consistent with Admati and Pfeiderer but consistent with Foster and Viswanathan (1990, 1993) in the case of the stock market.

The result for the Euro-USD trade is almost the same as is the case with the yen-dollar trade. In Table 4-2, a predicted negative relationship between number of price change and spread and between deals and spread is found. As shown in Panel A of Table 4-2, the Tokyo opening hour effect is not found between spread and price changes, except year 2001. However, between spread and deals, the Tokyo opening hour effect is seen 
as in Panel B of Table 4-2.

The hypothesis of a special first hour effect, a positive correlation between the spread and activities - namely, the Tokyo opening effect, is not supported in spread and price changes relationship, but strongly seen between spread and deals. Deals are done even with a wider spread during the Tokyo opening hours.

\subsection{Does Monday Opening Effect exist in the FX market?}

It is also worth checking the Monday morning effect because Tokyo market opens for the first time of the week after a long weekend break. If orders accumulated during the weekend (about 35 hours) is much larger than those accumulated during the overnight gap (2-3 hours) between New York close and Tokyo open, then the first hour of Tokyo on Monday (Hour 0 in adjusted GMT) may be different, most likely with a much higher activity, from that hour on any other day of the week.

Here, the effect of Monday morning is examined using the Monday Hour 0 dummy in the following regression model:

$$
\begin{gathered}
\text { Spread }_{(t)}=a_{0}+\left(a_{1}+a_{2} \text { MonHOdum }\right) * \text { number of price changes }_{(t)}+\varepsilon_{(t)}, \\
\text { Number of deals }_{(t)}=a_{0}+\left(b_{1}+b_{2} \text { MonHOdum }^{*} \operatorname{spread}_{(t)}+\varepsilon_{(t)} .\right.
\end{gathered}
$$

MonHOdum takes 1 when the price changes (deals) is put in at Monday Hour 0 and 0 otherwise. The expected sign of coefficient $a_{l}\left(b_{l}\right)$ is negative, and that of MonHOdum is positive. Again, lagged dependent and independent variables are also included in each of regressions.

\section{Table 4-3 Table 4-4}

Overall, the results suggest the existence of Tokyo opening effect (HO dummy) and Monday opening effect (Monday H0 dummy) for both USD-JPY and Euro-USD deals. That is, market participants carry out orders even with relatively wider bid-ask spread during the Tokyo opening hours. However, we do not find strong opening effects in price changes.

As seen in Panel B of tables 4-1 and 4-3, coefficients of $b_{1}+b_{2}$ are strictly positive for USDJPY trades, as $b_{1}<0<b_{2}$ and $\left|b_{1}\right|<\left|b_{2}\right|$. In Hour 0 (Tokyo opening hour), unlike 
other hours, the wider spread induces more deals, and this is more so on Monday, as the difference $\left|b_{2}\right|-\left|b_{1}\right|$ is larger in Panel 4-3-B than Panel 4-1-B. A remarkable reversal of the sign of coefficient is found in the relationship between deals and spread for the USD-JPY transactions during the Tokyo opening hour, and in particular on Mondays.

In contrast, it is clear from Panel B of Tables 4-2 and 4-4 that for EUR-USD transaction, the $b_{1}+b_{2}$ remains negative, as is $b_{1}$, although $b_{2}>0$ is common to the case of Tables 4-1 and 4-3 (USD-JPY). Therefore, a large number of price changes raises spreads to some extent, and a number of deals increases even a wider spread during the Tokyo opening hours/Monday opening hours, although the negative correlation holds between spread and deals for EUR-USD transactions.

\section{London and New York opening effects}

Finally, we test the effect of opening hours of London and New York markets using one of the following specifications:

$$
y_{(t)}=\beta^{*} D_{1}+\gamma^{*} D_{2}+\varepsilon_{(t)}
$$

where $y$ is one of the three variables, number of price changes, the number of deals, or the bid-ask spread; and $D_{1}$ and $D_{2}$ are dummy vectors. The relative volume is included as an explanatory variable to represent the depth of the market. $D_{l}$ consists of dummy variables representing Hour 0 to Hour 23 to control the hour of the day effects. $D_{2}$ are dummy vectors that examine opening and lunch hours over and above the GMT hour effect, as will be explained below. Opening hours of London and New York can be identified separately from the GMT hour dummies because the opening hour shifts by one hour between summer and winter. Since the Tokyo market does not observe the daylight saving time, the Tokyo local time does not shift against GMT hour, and therefore we use the dummy vector $D_{2}$ that identifies the London opening, London lunch, and New York opening over and above k hours after the Tokyo opens regardless of the daylight saving time. Here, $D_{2}$ can be written as follows: 


$$
D_{2}=\left|\begin{array}{llll:llll}
0 & & 0 & 1 & 0 & 0 & & 0 \\
& \ddots & & 1 & 0 & & \ddots & \\
0 & & 0 & 1 & 0 & 0 & & 0 \\
\hdashline 0 & & 0 & 0 & 1 & 0 & & 0 \\
& \ddots & & 0 & 1 & & \ddots & \\
0 & & 0 & 0 & 1 & 0 & & 0
\end{array}\right| .
$$

The $\mathrm{D}_{2}$ variables include the following open and lunch hour dummy variables. For example, as lunch breaks in London seem to begin at GMT Hour 10 in summer and GMT Hour 11 in winter, the London lunch dummy takes the following expression:

$$
\text { LN lunch }=\left\{\begin{array}{l}
1 \text { at Hour } 10 \text { in summer } \\
1 \text { at Hour } 11 \text { in winter } \\
0 \text { otherwise. }
\end{array}\right.
$$

Since $d y / d D_{2}=\gamma$ is independent from other explanatory variables, it simply depicts the effect of London lunch (London opening, NY opening) over and above the GMT Hour effect. $^{28}$

In running regressions, opening hours of two major markets are considered along with the London lunch time. Therefore, the London opening dummy takes the form:

$$
\text { LDN open } 1=\left\{\begin{array}{c}
1 \text { at Hour } 7 \text { in summer } \\
1 \text { at Hour } 8 \text { in winter } \\
0 \text { otherwise. }
\end{array}\right.
$$

Since a large jump of quote entries between hour 5 and hour 6 in summer (which corresponds to the London 5 and 6 hour in the morning) and between hour 6 and hour 7 in winter is in some cases found in Figures 2-1 to 2-4, we consider the case where the London market opens at Hour 6 in summer and Hour 7 in winter.

\footnotetext{
${ }^{28}$ The test is conducted including three other sets of dummies: London opening(version 2) $=1$ at Hour 6 in summer, 1 at Hour 7 in winter, and 0 otherwise; NY open (version 2)=1 at Hour 14 in summer, 1 at Hour 15 in winter, and 0 otherwise; NY open (version 3)= 1 at Hour 13 in summer, 1 at Hour 14 in winter, and 0 otherwise. The results are not reported to save space, but it is found that each of the London opening, London lunch, and NY opening has a significant effect on both price changes and spread, and that the opening (lunch) hours significantly shift with the daylight saving time.
} 
LDN open $2=\left\{\begin{array}{c}1 \text { at Hour } 6 \text { in summer } \\ 1 \text { at Hour } 7 \text { in winter } \\ 0 \text { otherwise, }\end{array}\right.$

It is not exactly clear from the Figures which hour is the New York opening hour, and therefore we consider three types of the New York opening dummies as follows:

$$
\begin{aligned}
& \text { NY open } 1=\left\{\begin{array}{l}
1 \text { at Hour } 14 \text { in summer } \\
1 \text { at Hour } 15 \text { in winter } \\
0 \text { otherwise, }
\end{array}\right. \\
& \text { NY open } 2=\left\{\begin{array}{l}
1 \text { at Hour } 13 \text { in summer } \\
1 \text { at Hour } 14 \text { in winter } \\
0 \text { otherwise, }
\end{array}\right. \\
& \text { NY open } 3=\left\{\begin{array}{l}
1 \text { at Hour } 12 \text { in summer } \\
1 \text { at Hour } 13 \text { in winter } \\
0 \text { otherwise, }
\end{array}\right.
\end{aligned}
$$

\section{Regression results}

Regression results for the USD-JPY pair are shown in Table 5-1. Panel A shows the result of Number of Price Changes. The results generally show that the Hour dummy variables are significant most of the time. The London open dummies, London lunch dummy, and New York open dummies are all significant and positive. The results indicate that the London opening effect and New York opening effect, after controlling for the GMT Hour effect and the trading volume effect, are clearly identified. The number of price changes are estimated approximately 25-30\% larger during opening hours than other business hours. The London lunch dummy is estimated significantly negative as expected.

The middle panel summarizes regression results of the number of deals. The GMT hour effects are significant, and the opening hours of London and New York as well as London Lunch hours are significant and have expected signs. The number of deals becomes 35-43\% larger during the opening hours. 
The bottom panel shows the regression result of the spread. Results show that the GMT hour dummy variables as well as London Lunch effect are significant in all of the regressions, whereas London and New York opening effects are insignificant in 2000 and 2001. The spread is estimated more than 3\% narrower during the opening hours. In particular, it drops by more than 6\% during New York opening hours. The opening hour effects are significantly negative in 1999, indicating that the spread becomes narrower at the beginning of London and New York markets. However, coefficients of opening are found insignificant in 2000 and in 2001. This suggests that it is difficult to infer from the movement of the spread when the London and New York market opens in 2000 and 2001. The width of spread is not significantly different from other hours even during the opening hours of London and New York. Contrary to the opening hour effects, London lunch hour is estimated significantly positive in all regressions. The result means the evidence of wider spread during lunch break.

\section{Table 5-1}

Regression results of the Euro-USD pair are shown in Table 5-2. The result of regression of the Number of Price Changes is provided in the upper panel. The results show that the Hour dummy variables, as well as the London open dummies, London lunch dummy and New York open dummies are significant.

The middle panel in Table 5-2 provides the results of the Number of Deals. All of the coefficients are significant and have expected signs.

The result of Bid-ask Spread is summarized in the bottom panel. Although the Hour dummies are all significant, London and New York opening dummies and London lunch dummies are insignificant in most cases. In contrast to the result of USD-JPY pair, the width of spread is not significantly different from other business hours even during the opening hours of London and New York.

\section{Table 5-2}

Both the lack of the upswing of the U-shape in the afternoon for the trading activities and the insignificant market open effects on bid-ask spread in New York market may be due to the recent widespread practice of continuous trading and better control of inventory. The U-shape, in particular the increase in the afternoon, is often regarded as 
willingness to trade in order to control inventory ahead of a long break (between the days or over the weekend). However, the widespread use of the trading systems like the EBS system and the computer programs made it much easier for dealers and proprietary traders to find market rates and counterparties even in other regions of the world regardless of the local hours and to manage inventories continuously. This may have contributed to the disappearance of the pick up of the activities toward the end of the business hours in New York, and little changes of the bid-ask spread during the business hours from Tokyo, London, and New York. ${ }^{29}$

\section{Conclusion}

In this paper, the intra-daily patterns were investigated from the rich data sets of EBS quotes, deals and relative trading shares. Some of the findings are well-known such as the high activities at the opening of the market, high correlations between quote entries and deals, and higher activities being associated with narrow spreads. However, some of the findings are somewhat surprising. The following observations are new in the literature.

First, there is no U-shape intraday activity pattern in the dollar/yen or euro/dollar market in New York market. The activities are high during the opening hours but not ending hours. Careful observations on the peak of activities, exploiting the difference between Tokyo and New York in adoption of summer (daylight saving) and winter time to conclude where the activities originate during the overlapping business hours. There is no surge in activities toward the end of the New York afternoon hours. Even on Fridays, there is no pick up in activities in the NY afternoon hours.

Second, intra-day patterns of activities and bid-ask spreads are quite stable over the time (yearly comparison). Namely, the peak of activities is observed in the opening hours (9am in Tokyo; 8am in Europe/7am London, and 8-10am New York), and the troughs are late afternoon hours of New York, with significant drops during the lunch hours in Tokyo and, to the lesser extent, in European lunch hours.

Third, the bid-ask spread is generally negatively correlated with the indicator of activities: Higher activities are associated with narrow spreads and low activities are associated with wide spreads. However, the first hour, or to be more specific the first half hour of the Tokyo market (GMT Hour 0) has a slightly wider spread than other

${ }^{29}$ We thank Rich Lyons for his suggestion of this interpretation. 
hours of comparable activities.

Fourth, from observations of the figures, we found that a home-market bias in the foreign exchange market is significant. The yen is traded more by Tokyo financial institutions (Tokyo-Tokyo deals, Tokyo-London deals, in particular) and the euro is traded more by London financial institutions (London-London deals, London-New York deals, in particular). In total, about half of yen trades are attributable to the Tokyo financial institutions and more than half of euro trades are attributable to the London financial institutions.

Fifth, it is interesting to know that the overlapping business hours encourage inter-regional transactions and overall surges in activities. For both the yen and the euro, the London-New York deal share is the highest, and the Tokyo-New York deal share is the lowest. This may reflect the fact that participants from other regions may have different reactions to the same news, and resulting in the deal.

Sixth, a rigorous analysis of the opening hour effects of London and New York, and lunch hour effects of London, taking advantage of the one-hour shift between the regular and daylight saving times, we find that there are significant opening hour surge and lunch hour decline in activities (the number of deals and the number of price changes). However, there seems to be insignificant effects on the bid-ask spread from the London or New York openings or London lunch hour. These features are common between the yen and the euro trading.

Finally, a positive correlation between the price change and the inter-regional trading share was found for overlapping business hours between Tokyo and London, and also fo those between London and New York. When information, both private and public, available in the newly-opening market (e.g., London) is quite different from that had been known in the previously trading market (e.g., Tokyo), then inter-regional trading becomes more prevalent (relative to total volumes of transactions) in addition to the large change in prices during the overlapping business hours.

Although we have found several interesting facts in the newly available data, there are many tasks left for future research. First, changes in the exchange rate and an activity indicator may be correlated. If the deal is done on one side only, then the exchange rate may move toward that direction. The price impact of deals will be investigated in the 
future. Second, macroeconomic announcements are often planned during the hour that are before the market opening (say, 8:45 am). However, other markets are open in the case of foreign exchange markets. Additional activities on the day of announcements may be detected not in the market (say, NY) where it is announced but in other markets (say, London). 
References:

Admati, Anat R. and Paul Pfleiderer, “A Theory of Intraday Patterns: Volume and Price Variability,” Review of Financial Studies, (1988), vol. 1, no. 1: 3-40.

Andersen, Torben G. and Tim Bollerslev (1997). "Intraday Periodicity and Volatility Persistence in Financial Markets,” Journal of Empirical Finance, vol. 4: 115-158.

Andersen, Torben G. and Tim Bollerslev (1998). "Deutsche Mark-Dollar Volatility: Intraday Activity Patterns, Macroeconomic Announcements, and Longer Run Dependencies,” Journal of Finance, Vol. 53, Issue 1, February: 219-265.

Andersen, Torben G., Tim Bollerslev, Francis X. Diebold, and Clara Vega (2003). "Micro Effects of Macro Announcements: Real-Time Price Discovery in Foreign Exchange,” American Economic Review, vol. 93: 38-62.

Baillie, Richard T. and Michel M. Dacorogna (1997), eds., High Frequency Data in Finance, a conference volume Journal of Empirical Finance vol. 4, no. 2-3.

Baillie, Richard T. and Tim Bollerslev (1990). "Intra-Day and Inter-Market Volatility in Foreign Exchange Rates,” Review of Economic Studies, vol. 58: 565-585.

Bank of England (2004). The Foreign Exchange and Over-the-Counter Derivatives Markets in the United Kingdom, Bank of England Quarterly Bulletin, vol. 44: 470-484.

Bank of International Settlements (BIS) (2002). Triennial Central Bank Survey 2001 Triennial Central Bank Survey of Foreign Exchange and Derivatives Market Activity 2001 - Final Results, Basle: Bank of International Settlements, March 18, 2002. [http://www.bis.org/publ/rpfx02.htm\#pgtop]

Bank of Japan (2001). Central Bank Survey of Foreign Exchange and Derivatives Market Activity in April 2001: Turnover Data, Japan, Tokyo: Bank of Japan, October 10, 2001. [http://www.boj.or.jp/en/ronbun/ronbun_f.htm]

Berger, David, Alain P. Chaboud, Sergey V. Chernenko, Edward Howorka,Raj S. 
Knshnasami Iyer, David Liu, and Jonathan H. Wright, (2005). "Order flow and Exchange Rate Dynamics in Electronic Brokerage System Data,” Board of Governors of the Federal Reserve System International Finance Discussion Papers No.830, April.

Bollerslev, Tim and I. Domowitz, (1993). "Trading Patterns and Prices in the Interbank Foreign Exchange Market,” Journal of Finance, vol. 48: 1421-1443.

Brock, W. A. and A. Kleidon, (1992). "Periodic Market Closure and Trading Volume: A Model of Intraday bids and asks,” Journal of Economic Dynamics and Control, vol. 16: 451-489.

Chaboud, Alain P.; Sergey V. Chernenko, Edward Howorka; Raj S. Krishnasami Iyer, David Liu and Jonathan H. Wright, 2004. "The High-Frequency Effects of U.S. Macroeconomic Data Releases on Prices and Trading Activity in the Global Interdealer Foreign Exchange Market,” Board of Governors of the Federal Reserve System, International Finance Discussion Papers, Number 823, November.

Covrig, Vicentiu and Michael Melvin, (2005), “Tokyo Insiders and the Informational Efficiency of the Yen/Dollar Exchange Rate,” International Journal of Finance and Economics, vol. 10, 185-193.

Dufour, Alfonso and Robert F. Engle, (2000). “Time and the Price Impact of a Trade," Journal of Finance, Vol.55, Issue 6, 2467-2498.

Easley, David and Maureen O’Hara, (1992). “Time and the Process of Security Price Adjustment,” Journal of Finance, vol. XLVII, no.2, June: 577-605.

Engle, Robert F. and Andrew J. Patton, (2004). "Impacts of Trades in an Error Correction Model of Quote Prices,” Journal of Financial Market, Vol 7, Issue 1, 1-25.

Faust, Jon; John H. Rogers, Shing-Yi B. Wang, and Jonathan H. Wright, (2003). "The High Frequency Response of Exchange Rates and Interest Rates to Macroeconomic Announcements," Board of Governors of the Federal Reserve System, International Finance Discussion Papers, no. 784, October.

Foster, F. Douglas, and S. Viswanathan, (1990). “A Theory of the Interday Variations in 
Volume, Variance, and Trading Costs in Securities Markets,” Review of Financial Studies, vol. 3, no.4: 593-624.

Foster, F. Douglas, and S. Viswanathan, (1993). "Variations in Trading Volume, Return Volatility, and Trading Costs: Evidence on Recent Price Formation Models,” Journal of Finance, 48, 187-211.

Goodhart, Charles; Takatoshi Ito; and Richard Payne, (1996) “One Day in June 1993: A Study of the Working of the Reuters 2000-2 Electronic Foreign Exchange Trading System,” in J. A. Frankel, G. Galli, and A. Giovannini (eds.) The Microstructure of Foreign Exchange Markets, Chicago: The University of Chicago Press: 107-179.

Goodhart, Charles and Richard Payne, (1996) "Microstructural Dynamics in a Foreign Exchange Electronic Broking System” Journal of International Money and Finance, vol. 15, no. 6: 829-852.

Goodhart, Charles, A.E. and Maureen O’Hara, (1997). “High Frequency Data in Financial Markets: Issues and Applications” Journal of Empirical Finance, vol. 4: 73-114.

Harris, Larry (1986). “A Transaction Data Survey of Weekly and Intraday Patterns in Stock Returns,“ Journal of Financial Economics, Vol.16, 99-117.

Hsieh, David, (1988). "The Statistical Properties of Daily Foreign Exchange Rates, 1974-1983,” Journal of International Economics, vol. 24: 129-145.

Hsieh, David A. and Allan W. Kleidon, (1996). "Bid-Ask Spreads in Foreign Exchange Markets: Implications for Models of Asymmetric Information" in J. A. Frankel, G. Galli, and A. Giovannini (eds.) The Microstructure of Foreign Exchange Markets, Chicago: The University of Chicago Press: 41-67.

Ito, Takatoshi, Richard K. Lyons, and Michael T. Melvin, (1998). "Is There Private Information in the FX Market? The Tokyo Experiment”, Journal of Finance, vol. LIII, no. 3, June: 1111-1130.

Ito, Takatoshi and Yuko Hashimoto, (2004). "Microstructure of the Yen/Dollar Foreign 
Exchange Market: Patterns of Intra-day Activity in the Electronic Broking System” NBER working paper, no. 10856, October 2004.

Ito, Takatoshi and V. Vance Roley, (1987). "News from the U.S. and Japan: Which Moves the Yen/Dollar Exchange Rate?", Journal of Monetary Economics, vol. 19, March: 255-277.

Jones, Charles M., Gautam Kaul, and Marc Lipson (1994). “Transactions, Volume, and Volatility,” Review of Financial Studies, vol. 7, no. 4: 631-651.

Lyons, Richard (1995). “Tests of Microstructural Hypotheses in the Foreign Exchange Market,” Journal of Financial Economics, vol. 39: 321-351.

Lyons, Richard (1996). "Foreign Exchange Volume: Sound and Fury Signifying Nothing?” in J. A. Frankel, G. Galli, and A. Giovannini (eds.) The Microstructure of Foreign Exchange Markets, Chicago: The University of Chicago Press: 183-205.

Lyons, Richard (1997). “A simultaneous trade model of the foreign exchange hot potato”. Journal of International Economics 42, 275-2

Lyons, Richard (1998). “Profits and Position Control: A Week of FX dealing” Journal of International Money and Finance, vol. 17: 97-115.

Lyons, Richard (2001). The Microstructure Approach to Exchange Rates, Cambridge: MIT Press.

Osler, Carol L. (2005). "Stop-loss Orders and Price Cascades in Currency Markets," Journal of International Money and Finance, vol. 24: 219-241.

Wood, Robert, Thomas McInish, and Keith Ord (1985). "An Investigation of Transaction data on NYSE Stocks,” Journal of Finance, Vol.40, 723-741. 
Table 1: Data summary; Jan 1, 1999 - December 28, 2001

(Excluding Saturdays, Sundays, and national holidays in at least one of the three major markets)

(A) Quote and Deal data for the USD-JPY pair

Total number of seconds

$$
59,234,400
$$

Quote

Number of Price changes $\quad 7,514,064$

$\begin{array}{clr}\text { spread } & \text { mean } & 0.020668 \\ \text { median } & 0.02 \\ \text { variance } & 5.426400 \mathrm{E}-05 \\ \text { skew } & 1.63961 \\ \text { kurtosis } & 9.94646\end{array}$

Deal

Number of deals bid-side only 2,746,195 ask-side only 2,618,326

(B) Quote and Deal data for Euro-USD pair

Total number of seconds

$59,234,400$

Quote

Number of Price changes $\quad 7,250,465$

$\begin{array}{clr}\text { spread } & \text { mean } & 0.00014998 \\ & \text { median } & 0.0001 \\ \text { variance } & 1.03247 \mathrm{D}-08 \\ \text { skew } & 4.07975 \\ \text { kurtosis } & 42.61309\end{array}$

Deal

Number of deals bid-side only $\quad 4,055,369$ ask-side only 4,161,367 
Table 2: Relative deal amount by region in the EBS Market.

(A)Relative volume for the USD-JPY pair

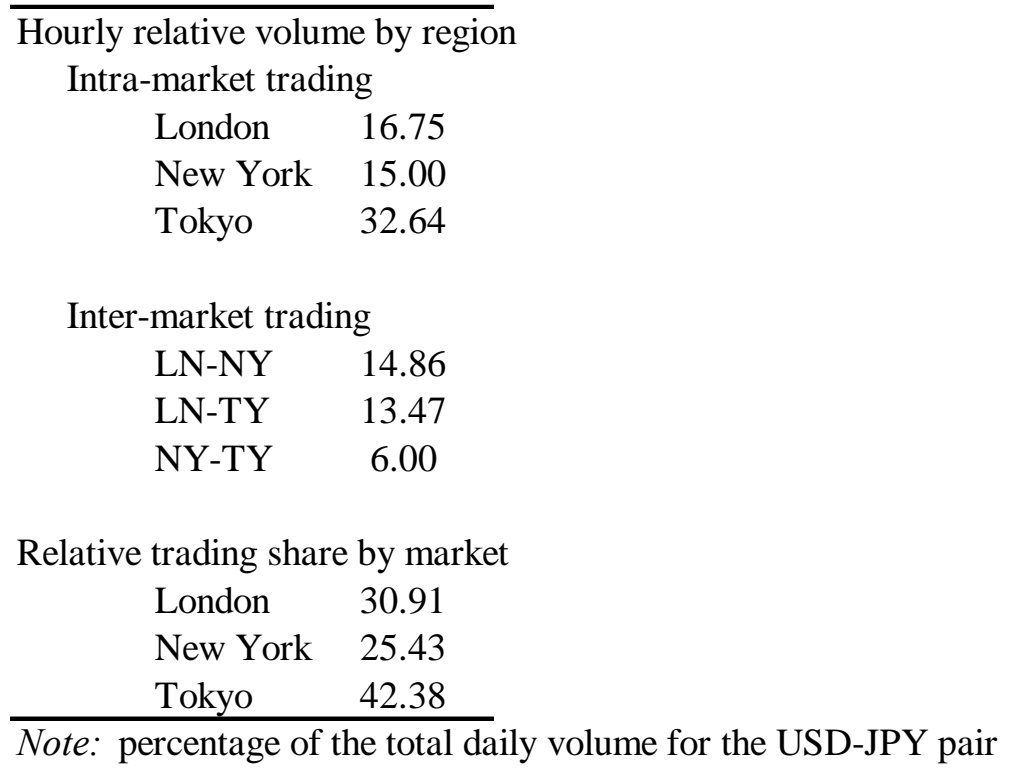

(B)Relative volume for the Euro-USD pair

\begin{tabular}{cc}
\hline $\begin{array}{c}\text { Hourly relative volume by region } \\
\text { Intra-market trading }\end{array}$ \\
London & 36.96 \\
New York & 18.54 \\
Tokyo & 7.78 \\
\multicolumn{3}{c}{ Inter-market trading } \\
L N-NY & 24.28 \\
LN-TY & 9.01 \\
NY-TY & 2.99 \\
\multicolumn{3}{c}{} \\
Relative trading share by market \\
London & 53.60 \\
New York & 32.18 \\
Tokyo & 13.79
\end{tabular}

Note: percentage of the total daily volume for the EUR-USD pair 
Table 3: Intraday timeline: GMT Clock and corresponding Local time of the three major markets

Normal (Winter)

\begin{tabular}{c|rrrrrrrrrrrrrrrrrrrrrrrr}
\hline GMT & 0 & 1 & 2 & 3 & 4 & 5 & 6 & 7 & 8 & 9 & 10 & 11 & 12 & 13 & 14 & 15 & 16 & 17 & 18 & 19 & 20 & 21 & 22 & 23 \\
\hline \hline Tokyo & 9 & 10 & 11 & 12 & 13 & 14 & 15 & 16 & 17 & 18 & 19 & 20 & 21 & 22 & 23 & +0 & +1 & +2 & +3 & +4 & +5 & +6 & +7 & +8 \\
\hline London & 0 & 1 & 2 & 3 & 4 & 5 & 6 & 7 & 8 & 9 & 10 & 11 & 12 & 13 & 14 & 15 & 16 & 17 & 18 & 19 & 20 & 21 & 22 & 23 \\
\hline NY & -19 & -20 & -21 & -22 & -23 & 0 & 1 & 2 & 3 & 4 & 5 & 6 & 7 & 8 & 9 & 10 & 11 & 12 & 13 & 14 & 15 & 16 & 17 & 18 \\
\hline
\end{tabular}

Daylight saving time (Summer)

\begin{tabular}{c|rrrrrrrrrrrrrrrrrrrrrrrr}
\hline GMT & 0 & 1 & 2 & 3 & 4 & 5 & 6 & 7 & 8 & 9 & 10 & 11 & 12 & 13 & 14 & 15 & 16 & 17 & 18 & 19 & 20 & 21 & 22 & 23 \\
\hline \hline Tokyo & 9 & 10 & 11 & 12 & 13 & 14 & 15 & 16 & 17 & 18 & 19 & 20 & 21 & 22 & 23 & +0 & +1 & +2 & +3 & +4 & +5 & +6 & +7 & +8 \\
\hline London & 1 & 2 & 3 & 4 & 5 & 6 & 7 & 8 & 9 & 10 & 11 & 12 & 13 & 14 & 15 & 16 & 17 & 18 & 19 & 20 & 21 & 22 & 23 & +0 \\
\hline NY & -20 & -21 & -22 & -23 & 0 & 1 & 2 & 3 & 4 & 5 & 6 & 7 & 8 & 9 & 10 & 11 & 12 & 13 & 14 & 15 & 16 & 17 & 18 & 19 \\
\hline
\end{tabular}

March-April 1 week (Daylight saving time in London and Winter time in New York)

\begin{tabular}{c|rrrrrrrrrrrrrrrrrrrrrrrrr}
\hline GMT & 0 & 1 & 2 & 3 & 4 & 5 & 6 & 7 & 8 & 9 & 10 & 11 & 12 & 13 & 14 & 15 & 16 & 17 & 18 & 19 & 20 & 21 & 22 & 23 \\
\hline \hline Tokyo & 9 & 10 & 11 & 12 & 13 & 14 & 15 & 16 & 17 & 18 & 19 & 20 & 21 & 22 & 23 & +0 & +1 & +2 & +3 & +4 & +5 & +6 & +7 & +8 \\
\hline London & 1 & 2 & 3 & 4 & 5 & 6 & 7 & 8 & 9 & 10 & 11 & 12 & 13 & 14 & 15 & 16 & 17 & 18 & 19 & 20 & 21 & 22 & 23 & +0 \\
\hline NY & -19 & -20 & -21 & -22 & -23 & 0 & 1 & 2 & 3 & 4 & 5 & 6 & 7 & 8 & 9 & 10 & 11 & 12 & 13 & 14 & 15 & 16 & 17 & 18 \\
\hline
\end{tabular}


Table 4-1: Hour 0 Effect for USD-JPY trade

Panel A: Correlation between Number of Price change and Spread

\begin{tabular}{|c|c|c|c|c|c|c|c|}
\hline & Constant & s.e. & \# of price change & s.e. & H0 Dummy & s.e. & NOB \\
\hline Whole & $7.21 \mathrm{E}-03 * * *$ & $1.68 \mathrm{E}-04$ & $-6.16 \mathrm{E}-07$ *** & 2.39E-07 & $-1.76 \mathrm{E}-06 * * *$ & $3.31 \mathrm{E}-07$ & 16453 \\
\hline 1999 & 7.95E-03 *** & $3.26 \mathrm{E}-04$ & $-7.12 \mathrm{E}-07 *$ & 4.38E-07 & $-1.65 \mathrm{E}-06 * * *$ & $5.68 \mathrm{E}-07$ & 5321 \\
\hline 2000 & 8.03E-03 *** & 2.80E-04 & $-6.48 \mathrm{E}-07 *$ & 4.05E-07 & $-2.28 \mathrm{E}-06 * * *$ & 5.71E-07 & 5590 \\
\hline 2001 & $6.90 \mathrm{E}-03 * * *$ & 2.90E-04 & $-9.59 \mathrm{E}-07 * * *$ & 3.94E-07 & $-1.63 \mathrm{E}-06 * * *$ & $5.88 \mathrm{E}-07$ & 5542 \\
\hline
\end{tabular}

Panel B: Correlation between Number of Deals and Spread

\begin{tabular}{|c|c|c|c|c|c|c|c|}
\hline & Constant & s.e. & spread & s.e. & H0 Dummy & s.e. & NOB \\
\hline Whole & $217.3^{* * *}$ & 6.7 & $-4885.94 * * *$ & 321.3 & $17432.6 * * *$ & 465.3 & 16453 \\
\hline 1999 & $248.1 * * *$ & 13.5 & $-4782.55 * * *$ & 612.2 & $21343.6 * * *$ & 914.8 & 5321 \\
\hline 2000 & $230.2 * * *$ & 10.9 & $-5466.97 * * *$ & 510.8 & $14458.3 * * *$ & 712.7 & 5590 \\
\hline 2001 & $250.6 * * *$ & 11.1 & $-5364.02 * * *$ & 516.9 & $14437.8^{* * * *}$ & 742.1 & 5542 \\
\hline
\end{tabular}

Table 4-2 Hour 0 Effect for Euro-USD trade

Panel A: Correlation between Number of Price change and Spread

\begin{tabular}{rllllll|r}
\hline & Constant & s.e. & \# of price change & s.e. & H0 Dummy & s.e. & NOB \\
\hline whole & $1.55 \mathrm{E}-04 * * *$ & $2.17 \mathrm{E}-06$ & $-7.38 \mathrm{E}-08 * * *$ & $4.86 \mathrm{E}-09$ & $-2.02 \mathrm{E}-08 * *$ & $1.14 \mathrm{E}-08$ & 16444 \\
1999 & $1.64 \mathrm{E}-04^{* * *}$ & $3.93 \mathrm{E}-06$ & $-8.88 \mathrm{E}-08 * * *$ & $8.76 \mathrm{E}-09$ & $-2.82 \mathrm{E}-08 *$ & $1.88 \mathrm{E}-08$ & 5319 \\
2000 & $1.56 \mathrm{E}-04 * * *$ & $3.87 \mathrm{E}-06$ & $-8.28 \mathrm{E}-08 * * *$ & $8.57 \mathrm{E}-09$ & $-3.62 \mathrm{E}-08 *$ & $2.16 \mathrm{E}-08$ & 5586 \\
2001 & $1.48 \mathrm{E}-04 * * *$ & $3.49 \mathrm{E}-06$ & $-5.24 \mathrm{E}-08 * *$ & $7.90 \mathrm{E}-09$ & $5.16 \mathrm{E}-09$ & $1.90 \mathrm{E}-08$ & 5539 \\
\hline
\end{tabular}

Note: ${ }^{* * *},{ }^{* *}$ and ${ }^{*}$ indicate significance at the 1,5 , and $10 \%$, respectively.

Panel B: Correlation between Number of Deals and Spread

\begin{tabular}{|c|c|c|c|c|c|c|c|}
\hline & Constant & s.e. & spread & s.e. & H0 Dummy & s.e. & NOB \\
\hline whole & $204.3^{* * *}$ & 6.0 & $-355176^{* * *}$ & 22087.0 & 261160 *** & 64164.6 & 16444 \\
\hline 1999 & $195.8 * * *$ & 10.0 & $-353696 * * *$ & 36292.5 & $308779 * * *$ & 102842 & 5319 \\
\hline 2000 & $211.8 * * *$ & 10.3 & $-371868 * * *$ & 36702.6 & $169783 *$ & 123447 & 5586 \\
\hline 2001 & $209.6 * * *$ & 10.8 & $-344115 * * *$ & 42267.2 & 283027 **** & 107947 & 5539 \\
\hline
\end{tabular}


Table 4-3: Monday Opening effect for USD-JPY trade

Panel A: Correlation between the Number of Price changes and spread.

\begin{tabular}{|c|c|c|c|c|c|c|c|}
\hline & Constant & s.e. & \# of price change & s.e. & MonH0 Dummy & s.e. & NOB \\
\hline whole & $6.50 \mathrm{E}-03 * * *$ & $1.68 \mathrm{E}-04$ & $-2.27 \mathrm{E}-06 * * *$ & $2.21 \mathrm{E}-07$ & $1.64 \mathrm{E}-05 * * *$ & 7.30E-07 & 16453 \\
\hline 1999 & $7.10 \mathrm{E}-03 * * *$ & 3.27E-04 & $-2.68 \mathrm{E}-06 * * *$ & 4.01E-07 & $1.60 \mathrm{E}-05 * * *$ & 1.19E-06 & 5321 \\
\hline 2000 & 7.42E-03 $* * *$ & 2.82E-04 & $-2.21 \mathrm{E}-06 * * *$ & $3.80 \mathrm{E}-07$ & $1.45 \mathrm{E}-05 * * *$ & $1.27 \mathrm{E}-06$ & 5590 \\
\hline 2001 & $6.10 \mathrm{E}-03 * * *$ & 2.92E-04 & $-2.24 \mathrm{E}-06 * * *$ & 3.69E-07 & 1.83E-05 *** & $1.39 \mathrm{E}-06$ & 5542 \\
\hline
\end{tabular}

Panel B: Correlation between Number of Deals and spread

\begin{tabular}{|c|c|c|c|c|c|c|c|}
\hline & Constant & s.e. & spread & s.e. & MonH0 Dummy & s.e. & NOB \\
\hline Whole & $222.9 * * *$ & 7.0 & $-6618.2 * * *$ & 334.7 & $23085.5 * * *$ & 1138.9 & 16453 \\
\hline 1999 & $244.8 * * *$ & 14.2 & $-6883.0 * * *$ & 640.4 & 29225.2 *** & 2245.2 & 5321 \\
\hline 2000 & $242.0 * * *$ & 11.2 & $-6930.6 * * *$ & 528.5 & $17659.8 * * *$ & 1653.6 & 5590 \\
\hline 2001 & $264.0 * * *$ & 11.5 & $-6740.9 * * *$ & 537.2 & $17689.7 * * *$ & 1905.3 & 5542 \\
\hline
\end{tabular}

Note: ${ }^{* * *},{ }^{* *}$ and $*$ indicate significance at the 1,5 , and $10 \%$, respectively.

Table 4-4: Monday Opening effect for Euro-USD trade

Panel A: Correlation between the Number of Price changes and spread.

\begin{tabular}{|c|c|c|c|c|c|c|c|}
\hline & Constant & s.e. & \# of price change & s.e. & MonH0 Dummy & s.e. & $\mathrm{NOB}$ \\
\hline whole & $1.55 \mathrm{E}-04 * * *$ & 2.15E-06 & $-7.46 \mathrm{E}-08 * * *$ & 4.82E-09 & $-3.60 \mathrm{E}-08 *$ & $2.58 \mathrm{E}-08$ & 16444 \\
\hline 1999 & 1.63E-04 *** & 3.91E-06 & $-9.10 \mathrm{E}-08 * * *$ & 8.64E-09 & $-1.22 \mathrm{E}-08$ & 4.24E-08 & 5319 \\
\hline 2000 & $1.55 \mathrm{E}-04 * * *$ & 3.84E-06 & $-8.41 \mathrm{E}-08 * * *$ & 8.51E-09 & $-5.64 \mathrm{E}-08$ & $4.84 \mathrm{E}-08$ & 5586 \\
\hline 2001 & $1.48 \mathrm{E}-04 * * *$ & 3.47E-06 & $-5.13 \mathrm{E}-08 * * *$ & 7.83E-09 & $-4.45 E-08$ & $4.28 \mathrm{E}-08$ & 5539 \\
\hline
\end{tabular}

Panel B: Correlation between Number of Deals and spread

\begin{tabular}{crrrrrr|r}
\hline \multicolumn{2}{r}{ Constant } & s.e. & \multicolumn{1}{c}{ spread } & s.e. & MonH0 Dummy & s.e. & NOB \\
\hline whole & $205.8 * * *$ & 6.0 & $-350216^{* * *}$ & 22058.0 & $328091 * *$ & 159779 & 16444 \\
1999 & $197.6 * * *$ & 10.0 & $-347997 * * *$ & 36263.1 & $342864 *$ & 244451 & 5319 \\
2000 & $213.2 * * *$ & 10.2 & $-370781^{* * *}$ & 36697.9 & 220876 & 295604 & 5586 \\
2001 & $210.3 * * *$ & 10.8 & $-333859 * * *$ & 42077.9 & $416122 *$ & 291152 & 5539 \\
\hline
\end{tabular}


Table 5-1: London and New York markets Effects for USD-JPY pair

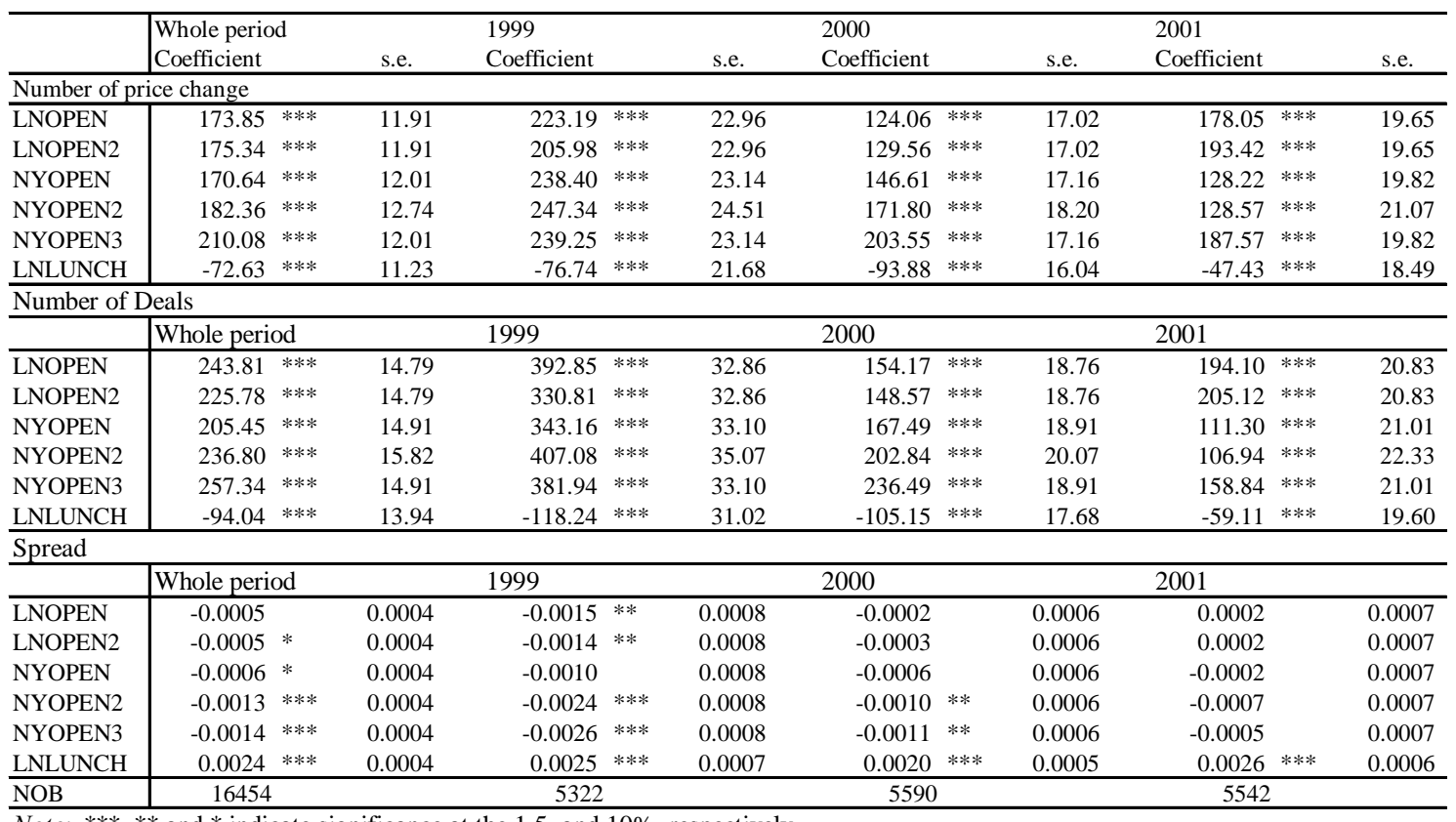

Note: ${ }^{* * *}, * *$ and $*$ indicate significance at the 1,5 , and $10 \%$, respectively.

Table 5-2: London and New York markets Effects for Euro-USD pair

\begin{tabular}{|c|c|c|c|c|c|c|c|c|c|c|c|}
\hline & $\begin{array}{l}\text { Whole period } \\
\text { Coefficient }\end{array}$ & s.e. & $\begin{array}{l}1999 \\
\text { Coefficient }\end{array}$ & & s.e. & $\begin{array}{l}2000 \\
\text { Coefficient }\end{array}$ & & s.e. & $\begin{array}{l}2001 \\
\text { Coefficient }\end{array}$ & & s.e. \\
\hline \multicolumn{12}{|c|}{ Number of price change } \\
\hline LNOPEN & $132.45^{* * *}$ & 9.40 & 118.05 & $* * *$ & 15.82 & 88.91 & $* * *$ & 15.99 & 190.25 & $* * *$ & 16.12 \\
\hline LNOPEN2 & $192.02 * * *$ & 9.40 & 172.76 & $* * *$ & 15.82 & 148.63 & $* * *$ & 15.99 & 254.28 & $* * *$ & 16.12 \\
\hline NYOPEN & $159.64 * * *$ & 9.48 & 124.68 & $* * *$ & 15.94 & 144.48 & $* * *$ & 16.12 & 209.52 & $* * *$ & 16.25 \\
\hline NYOPEN2 & $144.00 * * *$ & 10.06 & 93.41 & $* * *$ & 16.88 & 134.06 & $* * *$ & 17.10 & 204.33 & $* * *$ & 17.28 \\
\hline NYOPEN3 & $162.54 * * *$ & 9.48 & 133.90 & $* * *$ & 15.94 & 149.54 & $* * *$ & 16.12 & 204.49 & $* * *$ & 16.25 \\
\hline LNLUNCH & $-86.65^{* * *}$ & 8.86 & -104.27 & $* * *$ & 14.93 & -121.94 & $* * *$ & 15.07 & -33.42 & $* *$ & 15.16 \\
\hline \multicolumn{12}{|c|}{ Number of Deals } \\
\hline & Whole period & & 1999 & & & 2000 & & & 2001 & & \\
\hline LNOPEN & $362.30^{* * *}$ & 14.24 & 316.61 & $* * *$ & 23.76 & 300.50 & $* * *$ & 24.38 & 467.76 & $* * *$ & 24.23 \\
\hline LNOPEN2 & $310.31 * * *$ & 14.24 & 286.57 & $* * *$ & 23.76 & 245.09 & $* * *$ & 24.38 & 398.53 & $* * *$ & 24.23 \\
\hline NYOPEN & $347.04 * * *$ & 14.35 & 294.98 & $* * *$ & 23.94 & 370.94 & $* * *$ & 24.58 & 371.55 & $* * *$ & 24.44 \\
\hline NYOPEN2 & $336.77 * * *$ & 15.23 & 278.06 & $* * *$ & 25.36 & 366.85 & $* * *$ & 26.08 & 362.24 & $* * *$ & 25.98 \\
\hline NYOPEN3 & $361.20 * * *$ & 14.35 & 304.40 & $* * *$ & 23.94 & 367.54 & $* * *$ & 24.58 & 408.96 & $* * *$ & 24.44 \\
\hline LNLUNCH & $-212.91 * * *$ & 13.42 & -244.44 & $* * *$ & 22.43 & -265.59 & $* * *$ & 22.98 & -129.55 & $* * *$ & 22.80 \\
\hline \multicolumn{12}{|l|}{ Spread } \\
\hline & Whole period & & 1999 & & & 2000 & & & 2001 & & \\
\hline LNOPEN & $-0.00001 *$ & 0.00001 & -0.00002 & $* *$ & 0.00001 & 0.000000 & & 0.00001 & -0.00001 & & 0.00001 \\
\hline LNOPEN2 & $-0.00001 *$ & 0.00001 & -0.00002 & $* *$ & 0.00001 & -0.000001 & & 0.00001 & -0.000003 & & 0.00001 \\
\hline NYOPEN & -0.000004 & 0.00001 & -0.00001 & & 0.00001 & -0.000005 & & 0.00001 & 0.000004 & & 0.00001 \\
\hline NYOPEN2 & 0.000002 & 0.00001 & -0.000002 & & 0.00001 & 0.000002 & & 0.00001 & 0.00001 & & 0.00001 \\
\hline NYOPEN3 & -0.000005 & 0.00001 & -0.000001 & & 0.00001 & -0.000003 & & 0.00001 & -0.00001 & & 0.00001 \\
\hline LNLUNCH & 0.00001 & 0.00001 & 0.00001 & & 0.00001 & 0.00001 & & 0.00001 & 0.000001 & & 0.00001 \\
\hline NOB & 16449 & & 5321 & & & 5587 & & & 5541 & & \\
\hline
\end{tabular}

Note: $* * *, * *$ and $*$ indicate significance at the 1,5 , and $10 \%$, respectively. 
Figure 1: Intraday Activities (USD-JPY), Winter 1999-2001

Statistics of activity, Winter 1999-2001

excluding Sundays and JP, UK, US holidays

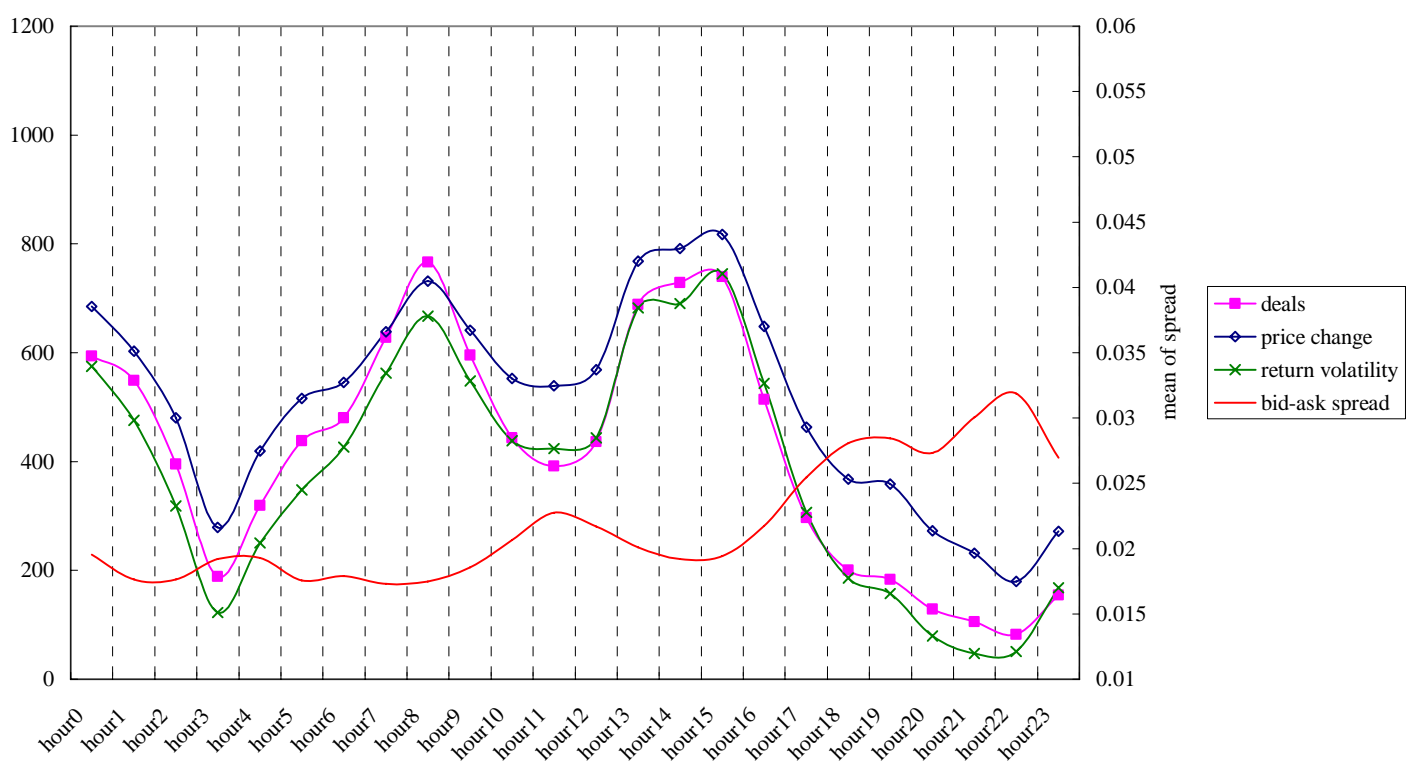

Figure 2: Intraday Activities (USD-JPY), Summer 1999-2001

Statistics of activity, Summer 1999-2001

excluding Sundays and JP, UK, US holidays

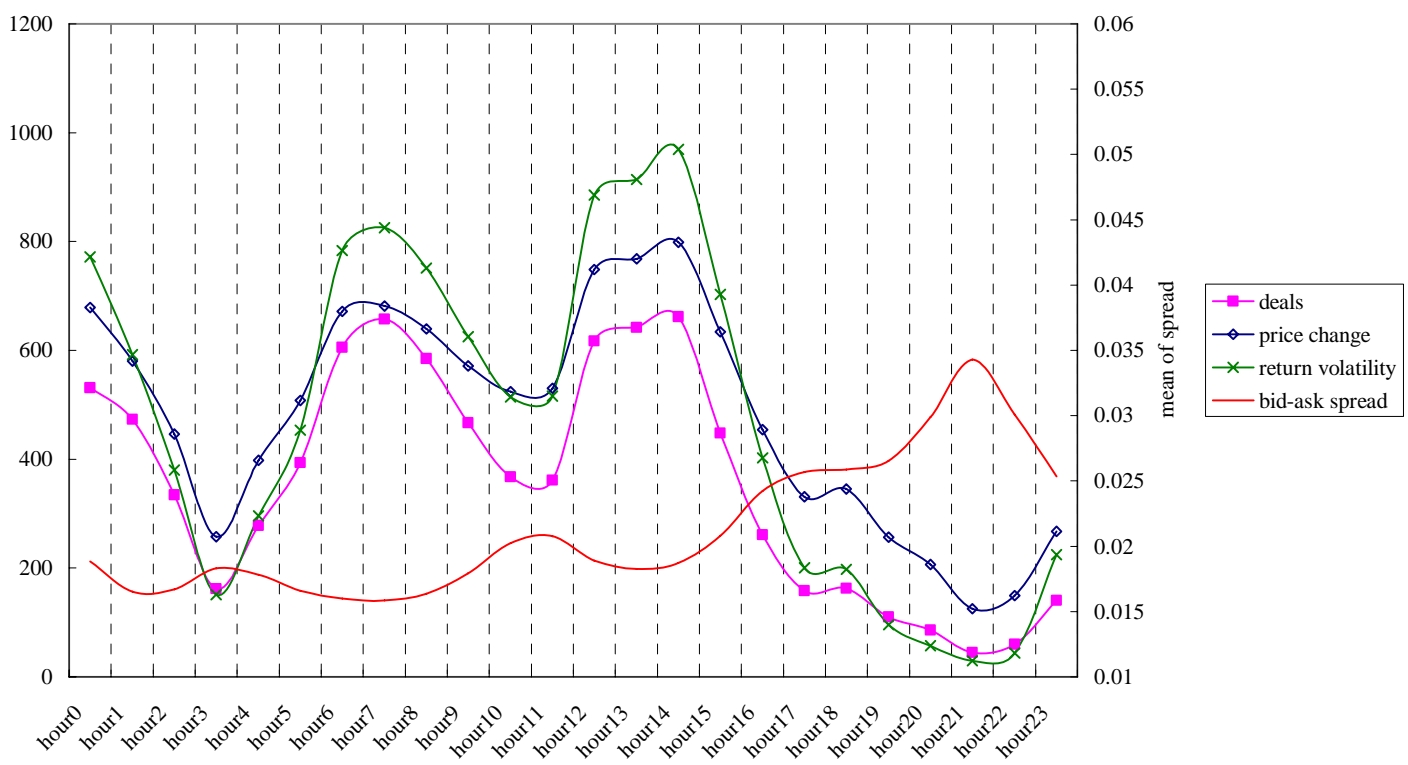


Figure 3: Intraday Activities (Euro-USD), Winter 1999-2001

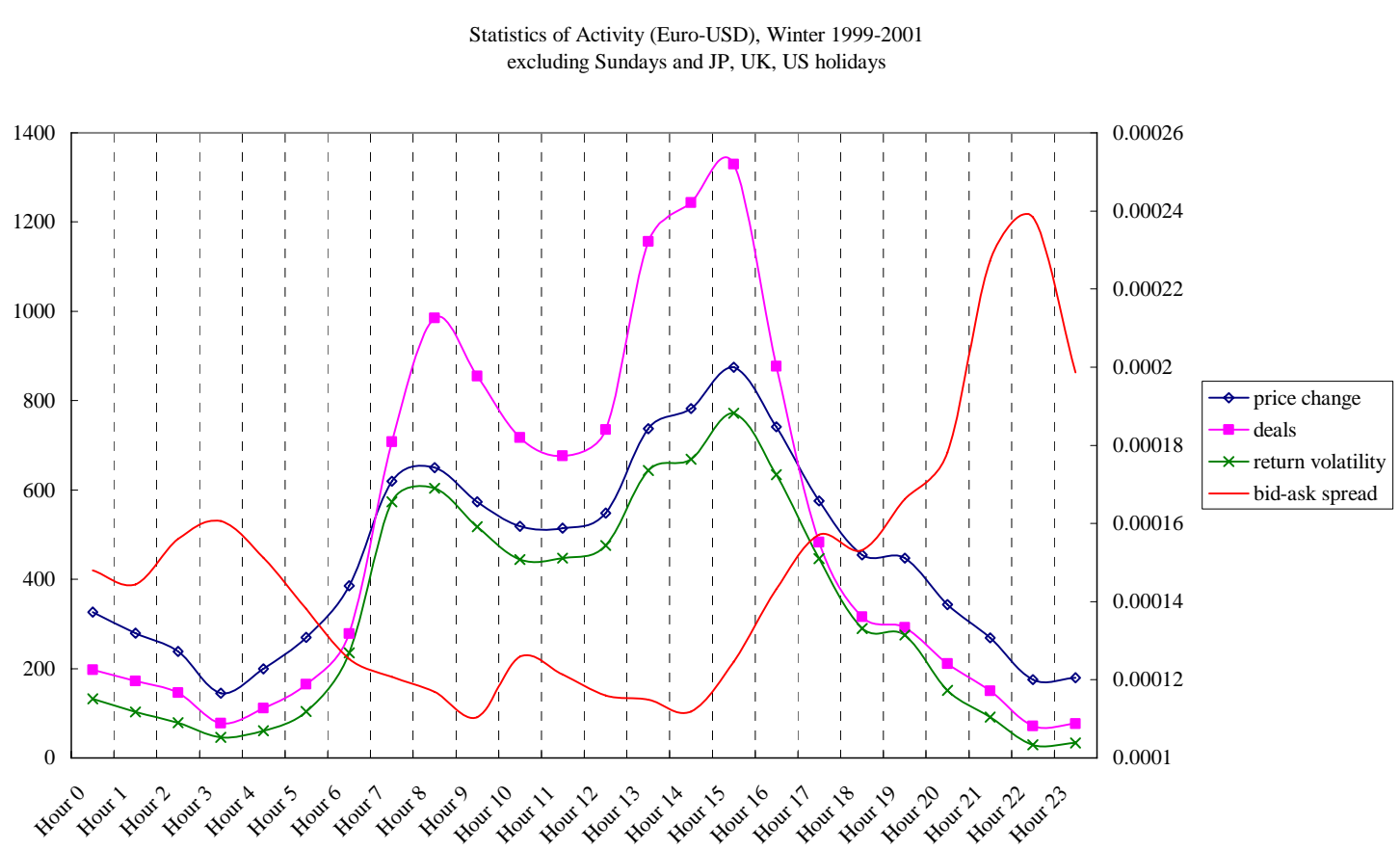

Figure 4: Intraday Activities (Euro-USD), Summer 1999-2001

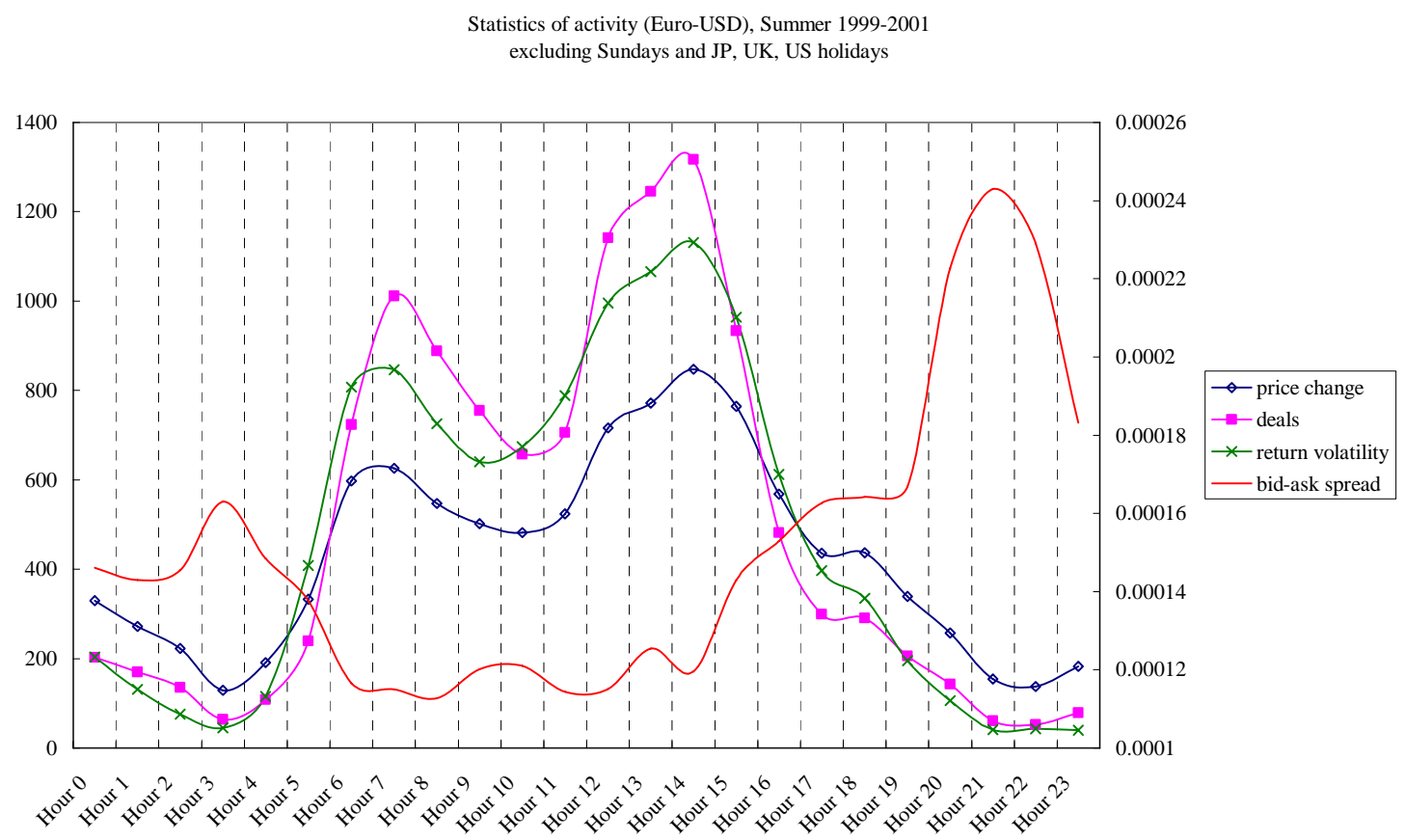


Figure 5: Relative volume (USD-JPY), Winter 1999-2001

Three Major Markets Traffic Pattern, Winter 1999-2001

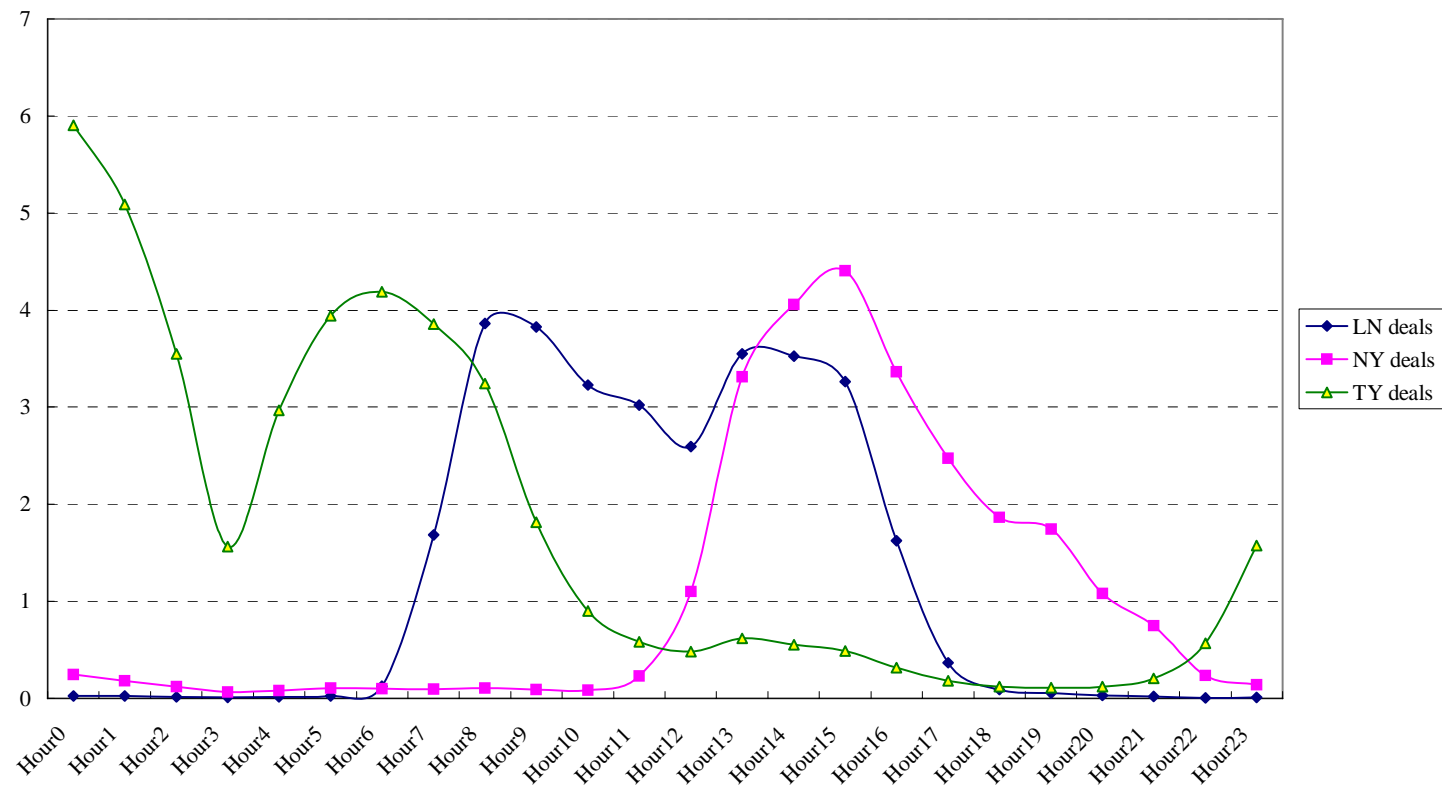

Figure 6: Relative volume (USD-JPY), Summer 1999-2001

Three Major Markets Traffic Pattern, Summer 1999-2001

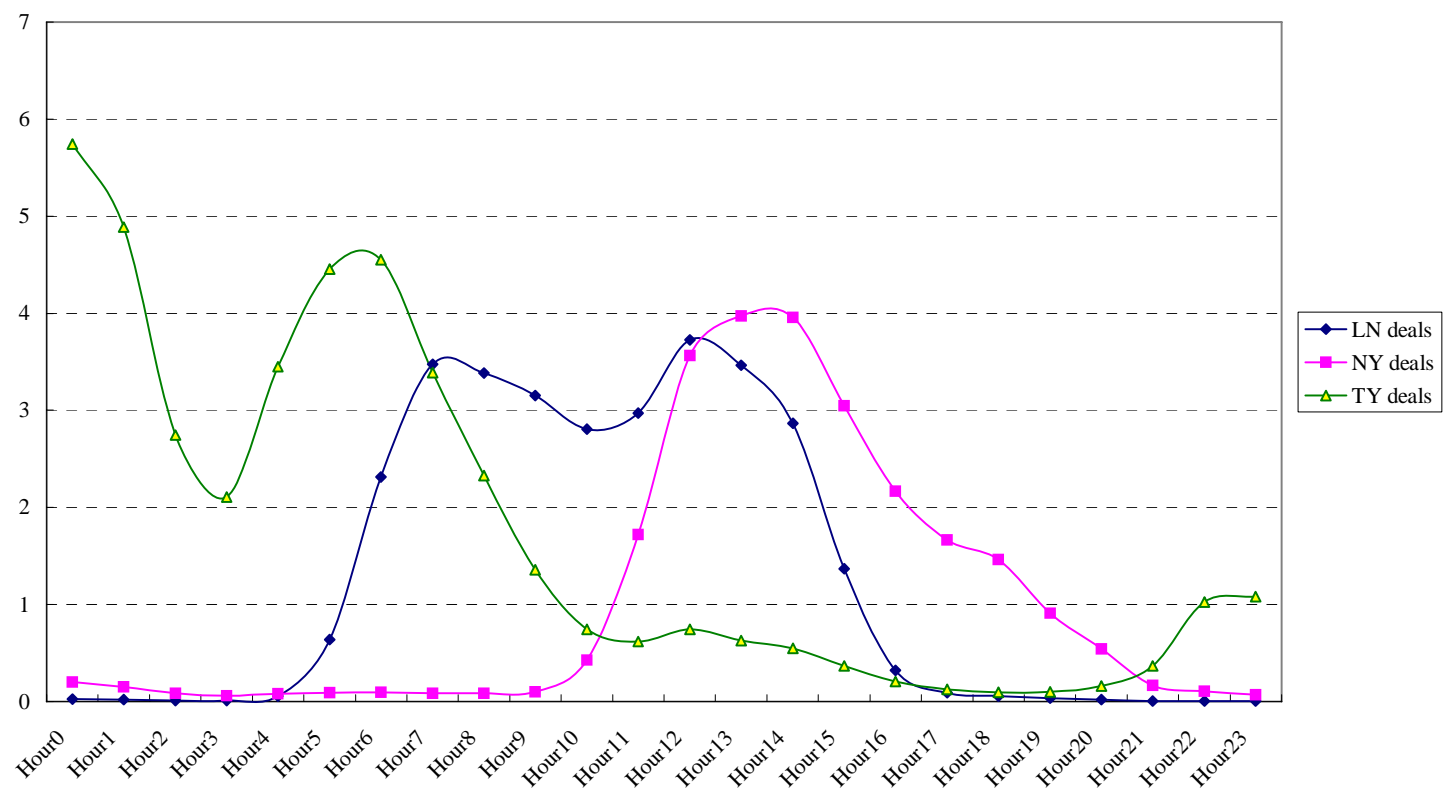


Figure 7: Relative volume (Euro-USD), winter 1999-2001

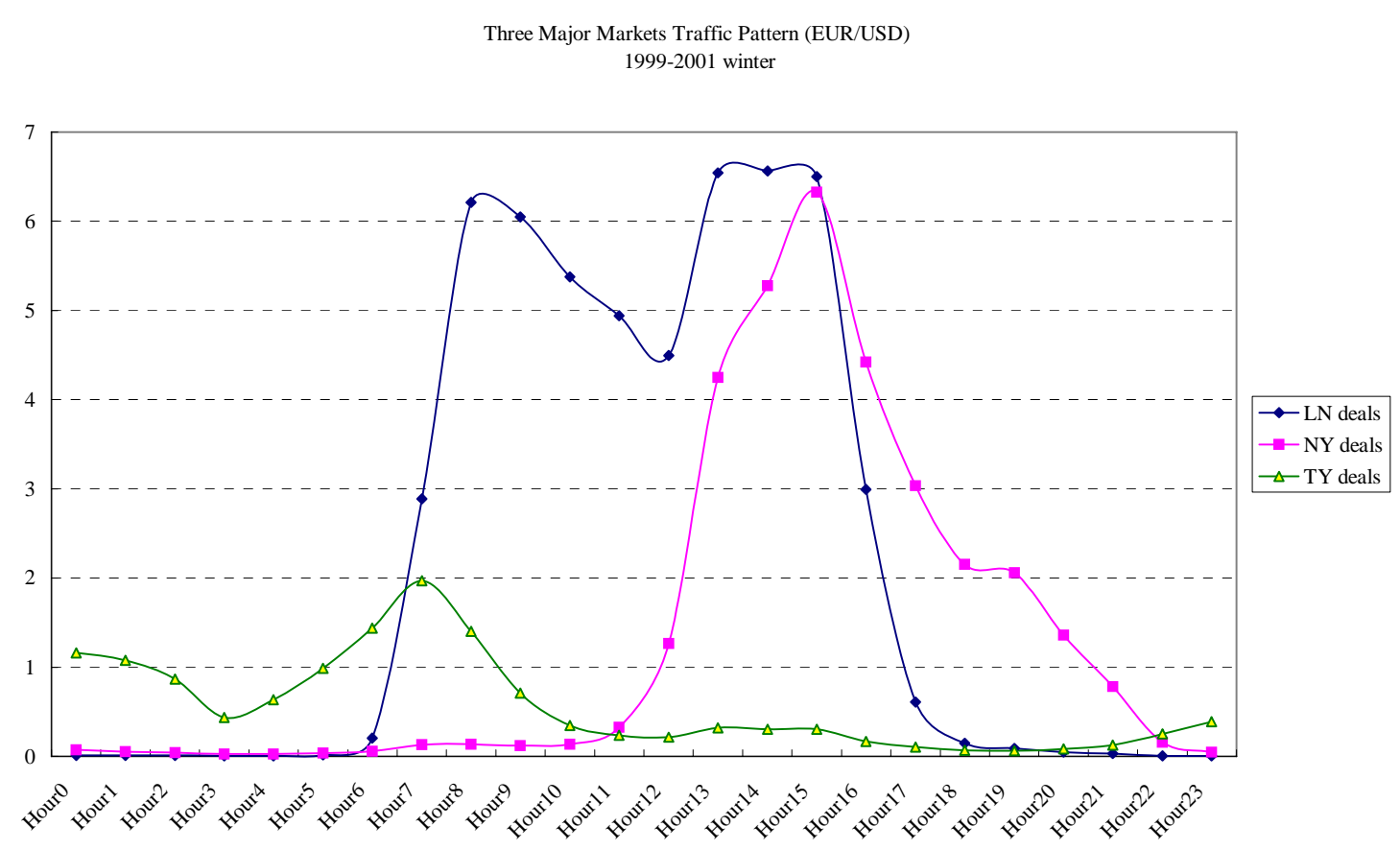

Figure 8: Relative volume(Euro-USD), summer 1999-2001

Three Major Markets Traffic Pattern (EUR/USD) 1999-2001 summer

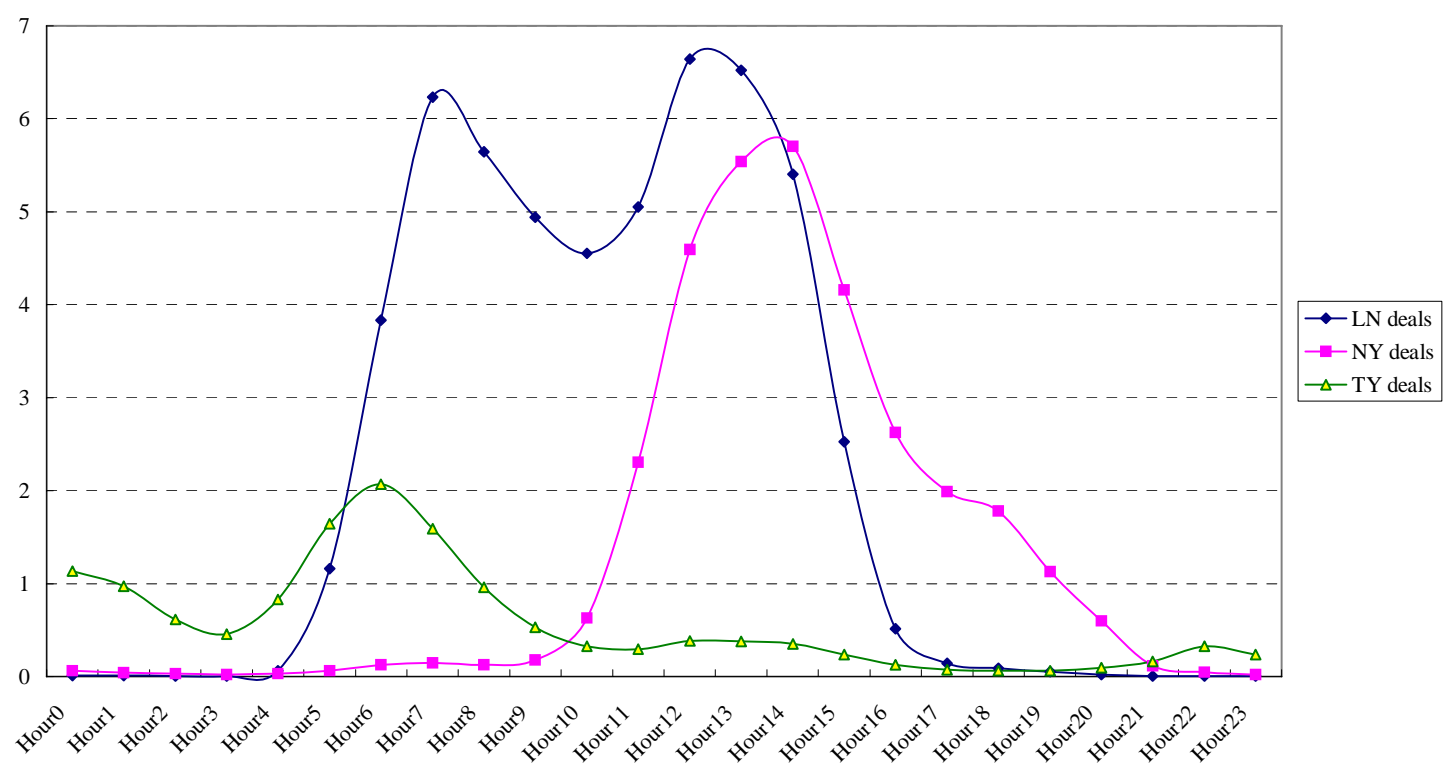

